\title{
Estratégias de reparo ao ataque ramificado CCV na aquisição fonológica
}

\author{
Repair strategies in the phonological \\ acquisition of $\mathrm{CCV}$ branching onsets
}

Andressa Toni

\begin{abstract}
Resumo
Este artigo aborda o desenvolvimento das sílabas CCV $\left(\right.$ Consoante $_{1}+$ Consoante $_{2}+$ Vogal) do Português Brasileiro na fala infantil. Presente em palavras como 'triste', 'bravo', 'blusa', 'madrinha', o ataque ramificado CCV é o último tipo silábico a ser adquirido pela criança, após os 5;0 anos de idade (LAMPRECHT, 1993). Contudo, palavras contendo CCV podem figurar como alvos na produção infantil mesmo antes dos 2;0 anos: 'ab(r)e aqui' (Lz.1;9 anos); '(o)b(r)igado' (Ar.1;9 anos). O objetivo deste trabalho é descrever as formas utilizadas pela criança durante o percurso de aquisição deste tipo silábico a fim de produzir os alvos CCV em sua fala. Foram observadas as seguintes estratégias de reparo na produção do ataque ramificado: metátese; epêntese; transposição; movimento recíproco; substituição $\mathrm{C}_{1}$ ou $\mathrm{C}_{2}$; apagamento $\mathrm{C}_{1}$ ou $\mathrm{C}_{2}$. Para examinar as propriedades e o momento de aplicação de tais estratégias, foram analisados dados experimentais de 49 sujeitos entre 2;4-5;10 anos, num teste de repetição de palavras abrangendo os contextos /p, b, t, d, k, g/ + /, r/. As palavras elicitadas permitiram observar o desenvolvimento também de sílabas de uso restrito na língua alvo, como /tl, dl/. Todos os dados foram verificados por meio do software Praat. Embora o apagamento $\mathrm{C}_{2}$ mantenha-se como o reparo mais recorrente, estratégias voltadas à modificação dos segmentos em $\mathrm{C}_{1}, \mathrm{C}_{2} \mathrm{e}$ a epêntese destacaram-se na produção dos sujeitos a depender do momento de desenvolvimento da estrutura CCV.
\end{abstract}

Palavras-chave: Aquisição fonológica; Sílaba; Estratégias de reparo.

\footnotetext{
* Universidade de São Paulo
} 
This article discusses the development of CCV syllables $($ Consonant $1+$ Consonant $2+$ Vowel) of Brazilian Portuguese in children's speech, as in words like 'triste' sad, 'bravo' angry, 'blusa' blouse, 'madrinha' godmother. CCV branched onset is the last syllable structure acquired by the child, after 5;0 years old (LAMPRECHT, 1993). However, words containing CCV syllables may appear as targets in children's production even before $2 ; 0$ years old: 'ab(r) e aqui' open here (Lz.1;9 years old); ‘(o)b(r)igado' thank you (Ar.1;9 years old). The goal of this article is to describe the alternative forms used by the child during the development of this syllable type in order to produce the CCV targets in their speech. The following repair strategies to the branched onsets were verified in the corpus: metathesis; epenthesis; transposition; reciprocal movement; replacement of $\mathrm{C}_{1}$ or $\mathrm{C}_{2}$; erasure of $\mathrm{C}_{1}$ or $\mathrm{C}_{2}$. In order to analyse the characteristics and the moment of use of these alternative forms, we used experimental data of 49 subjects between 2;4-5;10 years old. The experimental study allowed us to observe the development of syllable patterns of restricted use in Brazilian Portuguese, as / $\mathrm{tl}$, dl/. All data were verified using Praat software. The results point out $\mathrm{C}_{2}$ erasure as the most recurrent strategy repair during the CCV acquisition course. However, strategies like replacement of $\mathrm{C}_{1}$ or $\mathrm{C}_{2}$ and ephentesis were highlighted in the data depending on the development moment of CCV syllable structure in the child's productions.

Key-words: Phonological acquisition; Syllable; Repair strategies 
A. TONI

Estratégias de reparo ao ataque ramificado $\mathrm{CCV}$ na aquisição fonológica
Revista Letras, Curitiba, UFPR, n. 96, pp.255-286, jul./dez. 2017 ISSN 2236-0999 (versão eletrônica)

\section{Introdução}

$\mathrm{P}$

ara produzir palavras contendo contextos fonéticos e/ou fonológicos que ainda não foram plenamente dominados no percurso de aquisição da linguagem, é típico da fala infantil apresentar estratégias que visam evitar a produção de determinados segmentos ou estruturas, suprimindo-as ou simplificando-as de forma a gerar um output adaptado do input. De acordo com Lamprecht (2004, p. 29), “a criança pequena depara-se com um conflito entre o sistema fonológico empregado em seu ambiente, (...) que é o alvo a ser atingido, e as limitações na sua capacidade de categorização, de articulação, de planejamento motor, de memória fonológica e de processamento auditivo". Redução de encontros consonantais, anteriorização, semivocalização, substituição ou apagamento de segmentos e sílabas, sonorização e dessonorização, metátese, epêntese e transposição silábicas são algumas das estratégias de reparo comuns na fala infantil, investigadas em estudos como Greenlee (1974), Teixeira (1988), Leonard (1997), Yavas, Hernandorena e Lamprecht (1991), Miranda (1996), Mota, Othero e Freitas (2001), dentre outros. Na aquisição do ataque ramificado $\mathrm{CCV}$ em que $\mathrm{C}_{1}$ é uma consoante oclusiva1, $\mathrm{C}_{2}$ é uma das líquidas $/ \mathrm{l}$, $\mathrm{s}$ e $\mathrm{V}$ é

1 Embora no Português Brasileiro também sejam fonotaticamente permitidas sílabas CCV compostas pelas fricativas /f, v/ em posição $\mathrm{C}_{1}$, optamos neste trabalho por discorrer somente acerca dos contextos oclusiva + líquida, uma vez que as distintas propriedades articulatórias e fonológicas das combinações fricativa + líquida exigiriam experimentos e metodologia de análise próprias a fim de estabelecer suas (des) semelhanças em relação à combinação oclusiva + líquida. 
a vogal núcleo da sílaba, tem-se na posição $\mathrm{C}_{2}$ o principal alvo das estratégias de reparo da criança - tal posição é em geral apagada ou tem seu segmento substituído por outro de mesma classe natural na produção infantil, conforme observa-se em estudos como Fikkert (1994) sobre o Holandês, Freitas (1997) sobre o Português Europeu e Miranda (1996), Ribas (2002), Toni (2016) sobre o Português Brasileiro. Tais adaptações input-output parecem, contudo, seguir o desenvolvimento da gramática infantil, constituindo-se como pistas acerca do percurso percorrido na aquisição fonológica da criança.

Neste artigo, dois tópicos serão abordados em relação às estratégias de reparo ao ataque ramificado: i) a variedade de formas alternativas com que a ramificação de ataque se manifesta na fonologia em desenvolvimento da criança, e ii) as modificações em seu uso ao longo do percurso aquisitivo. Para tanto, um corpus de metodologia experimental foi utilizado na pesquisa, elicitando palavras com contextos CCV. Conforme afirma Grolla (2009), métodos experimentais permitem que a forma e/ou o conteúdo das estruturas-alvo sejam controladas, isolando-as de fatores externos em geral indissociáveis da fala cotidiana - por exemplo, a conversação sobre objetos familiares, a frequência de uso da língua, a evitação de palavras com contextos fonológicos ainda não dominados pela criança, dentre outros. É também em vista da maior quantidade de dados-alvo que a metodologia experimental pode proporcionar ao pesquisador - quando comparada à coleta naturalística, por exemplo - que se faz possível examinar quais estratégias de reparo representam idiossincrasias ou preferências individuais de uma criança e quais podem refletir marcos comuns no desenvolvimento fonológico infantil. Desse modo, por meio das formas alternativas típicas da fala infantil, tem-se um recurso para acessar, indiretamente, o desenvolvimento do conhecimento da criança acerca, por exemplo, da presença de um segundo elemento em posição de ataque na estrutura silábica; quais segmentos podem ocupar esta posição silábica; quais segmentos em $\mathrm{C}_{1}$ podem combinar-se a ela; como contornar as dificuldades na articulação tautossilábica de duas consoantes, dentre outros tópicos de estudo.

Nas seções a seguir, tem-se em 2 uma breve discussão acerca da estrutura silábica de ataque ramificado CCV e sua aquisição; segue-se, em 3, a metodologia utilizada na pesquisa, para em 4 apresentarem-se os resultados experimentais observados. Por fim em 5 discutem-se os dados obtidos.

\section{Ataques ramificados CCV: propriedades e aquisição}

Segundo autores como Jakobson (1968), Câmara Jr. (1977), Nespor e Vogel (1982) e Bisol (1999), as regras fonotáticas que regem a fala e a formação lexical consolidam-se num sistema linguístico pautadas sob a mesma unidade fonológica: a sílaba. Esta seria a estrutura basilar de uma língua, responsável por 
A. TonI Estratégias de reparo ao ataque ramificado $\mathrm{CCV}$ na aquisição fonológica

organizar sua melodia segmental e suprassegmental. $\mathrm{Na}$ fala infantil, igualmente, a sílaba se configura como base dos primeiros processos de organização da informação linguística, norteando a apreensão do sistema fonológico da língua da criança.

O modelo silábico aqui adotado é aquele descrito por Selkirk (1982), em que se atribuem à estrutura da sílaba dois aspectos ou componentes distintos: o molde silábico e os filtros segmentais - associação referida por Bisol (1999, p. 703) como "o conhecimento que o indivíduo tem da estrutura silábica de sua língua”. O molde silábico corresponde à ordenação dos subconstituintes da sílaba, organizados numa estrutura [[Ataque] [Rima [[Núcleo] [Coda]]]]o em que cada nó terminal pode ramificar-se; já os filtros segmentais determinam quais fonemas poderiam ser associados a cada slot ou nó terminal do molde.

A sílaba intuitivamente percebida na produção de uma palavra ou sentença é, ainda, fruto de outras duas instruções mentais, segundo Selkirk (1982): os princípios universais de silabificação e a regra de ressilabificação. Com base nessas instruções, o domínio da Sílaba define-se como o motivo pelo qual algumas combinações segmentais não podem ocorrer em determinadas posições estruturais e contextos de adjacência numa língua, mesmo pertencendo ao seu sistema sonoro. Por exemplo, segmentos como /r/ e /t/ não podem em Português ser arranjados numa ordem linear $/ \mathrm{r} /+/ \mathrm{t} /$ quando em condição tautossilábica, formando sílabas como */rta/, */rto/, */rte/; no entanto, quando em sílabas diferentes esta mesma ordem linear é permitida, como em 'carta', 'parto', 'Marte'. Já a ordem contrária seria permitida em condição tautossilábica, como em 'trapo', 'trovão', 'trem', mas não em condição heterossilábica, gerando termos malformados como */at.ras/, "/pot.ro/, "/vent.re/.

Enquanto os princípios de silabificação e ressilabificação estendem-se como universais fonológicos (cf. SELKIRK, 1982; BISOL, 1999; COLLISCHONN, 1999; SCHWINDT, 2001), a estrutura silábica molde + filtros apresenta formas e propriedades que variam de língua para língua, de maneira limitada. Os filtros segmentais se constituem de restrições responsáveis por impedir que determinadas combinações fonêmicas ocorram dentro de uma sílaba, ainda que essas restrições sejam permitidas pelo molde silábico da língua e não violem nenhum dos princípios de silabificação existentes num dado sistema fonológico. Por exemplo, Collischonn (1999) observa que sequências como */gnaw/ e */tniw/ seriam permitidas como ataques complexos pelo molde silábico do Inglês apesar de não serem reconhecidas como bem formadas pela fonotaxe dessa língua. Por outro lado, sequências como $/ \int \mathrm{l} / \mathrm{e} / \mathrm{\int} \mathrm{r} /$, embora presentes no Inglês em palavras como shrimp 'camarão' e schlep 'carregar', são consideradas como malformadas em Português Brasileiro - ainda que sequências de fricativa + líquida sejam consideradas bem formadas na língua portuguesa nos contextos /fr, fl, vr/. De forma análoga, enquanto as combinações presentes em 'fraco', 'flor', 'livro'

Revista Letras,

Curitiba, UFPR, n. 96, pp.255-286,

jul./dez. 2017 ISSN 2236-0999 (versão eletrônica) 
são aceitas como bem formadas em $\mathrm{PB}$, /vl/ é considerado como malformado, estando presente na língua somente em empréstimos, como em 'Vladimir'.

No molde silábico do $\mathrm{PB}$, a posição de ataque apresenta três diferentes padrões de produção, de acordo com Câmara Jr. (1977) e Bisol (1999): ataque simples $(\mathrm{CV})$, composto por um único segmento consonantal; ataque vazio $(\varnothing \mathrm{V})$, em que não haveria preenchimento dessa posição na sílaba; e ataque ramificado (CCV), composto por dois segmentos consonantais - uma obstruinte não estridente somada a uma líquida não nasal. Enquanto os ataques simples e vazios manifestam-se como as primeiras estruturas silábicas a emergir na produção infantil, tendo alta produtividade na fala adulta, o ataque complexo é o último tipo silábico a apresentar realizações regulares na fala da criança, mostrandose também pouco produtivo na língua alvo - cerca de 5\% dos dados, segundo Viaro e Guimarães-Filho (2007) e Marques (2008). ${ }^{2}$

Para Lamprecht (1993), a sílaba CCV constitui-se como a posição silábica de aquisição mais tardia no sistema fonológico infantil devido tanto à emergência das líquidas envolvidas no processo, $/$, r/, últimos segmentos estabilizados no inventário segmental da criança em contexto de ataque simples - somente aos 3;0 e 4;2 anos, respectivamente (MEZZOMO e RIBAS, 2004) -, quanto devido ao próprio desenvolvimento da ramificação de ataque, que exigiria também um planejamento articulatório mais complexo (YAVAS et al., 1991; GOLDSTEIN, 2003). Santos (1998) acrescenta, ainda, que por conta da relevância da rima na fonologia do $\mathrm{PB}$, envolvida na determinação do parâmetro do peso silábico e em regras como a acentuação, por exemplo, as posições de núcleo ramificado e coda precisariam, de fato, ser as primeiras a se estabilizar na fala infantil, e não o ataque ramificado - dado que esta é uma posição silábica que não se mostra envolvida em nenhum processo fonológico obrigatório no PB.

Embora seja uma estrutura de aquisição tardia, o surgimento das primeiras produções-alvo CCV é registrado já em fases iniciais da produção infantil aos 1;9 anos no corpus de Ribas (2002) e de Toni (2016). Nesse período entre o surgimento da produção CCV e a aquisição desse tipo silábico, é consenso na literatura que a redução do ataque ramificado (por meio do apagamento de $\mathrm{C}_{2}$ ) seria a forma de adequação input-output mais utilizada pela criança na tentativa de produzir o CCV, com porcentagens de aplicação a partir de 45\%, como a encontrada no estudo de Ferrante, Borsel e Pereira (2009), chegando à marca de 93\% de aplicação no estudo de Miranda (2007) e Baesso (2009) e 94\% em Miranda (1996). Contudo, além da redução também são mencionadas, na literatura, estratégias de reparo menos recorrentes na fala da criança, mas presentes tanto em dados de fala típica como desviante. Essas estratégias tomam como referência os conhecimentos fonéticos e fonológicos que as crianças já

2 Viaro e Guimarães-Filho (2007): 5,4\% do total de 150.875 palavras coletadas no dicionário Houaiss; Marques (2008): 5,78\% do total de 5.000 types coletados do banco de dados orais de Sardinha (1999). Estes valores percentuais se referem à soma de todas as estruturas de ataque ramificado coletadas nos corpora dos autores. Dessa forma, estes valores englobam, além da sílaba CCV, também as estruturas CCVC, CCVV e CCVVC, em Marques (2008); e CCVC, CCVG e CCVCC em Viaro e Guimarães-Filho (2007). 
A. TONI Estratégias de reparo ao ataque ramificado $\mathrm{CCV}$ na aquisição fonológica

desenvolveram sobre sua língua materna, especialmente sobre sua pauta rítmica e entoacional (LAMPRECHT, 2004, p. 28), podendo fornecer pistas acerca do grau de desenvolvimento da ramificação de ataque na fonologia infantil, pois podem indicar um reconhecimento da estrutura CCV - e, logo, do contraste entre sílabas CCV e CV - que seria anterior ao domínio da articulação correta do CCV, propriamente. Por exemplo, uma criança que, na tentativa de produzir um CCV como /br/, produz formas como ['bur.je] para 'bruxa', [ba'ra.vv] para 'bravo' ou ['bla.su] para 'braço', embora demonstre ainda não ter domínio sobre a produção da sílaba CCV, também demonstra certo conhecimento acerca da estrutura subjacente desse tipo silábico - manifestando, por exemplo, um reconhecimento de que esta sílaba é composta por dois segmentos consonantais, uma oclusiva labial e uma líquida, que devem ser produzidas em sequência. Visando evitar o ataque ramificado $/ \mathrm{br} /$, a criança manipula a sequência $/ \mathrm{b} /+$ /r/ de forma a não produzir uma estrutura CCV, mas sim uma estrutura CVC ou CV.CV, nos dois primeiros casos, ou de forma a produzir uma combinação segmental diferente do alvo, no último caso - com um segmento da mesma classe natural do alvo, mas que seria considerado "facilitador" (RIBAS, 2002, 2006; HERNANDORENA e LAMPRECHT, 1997). Desse modo, observar o período de surgimento destas manipulações silábicas, assim como sua natureza, poderia auxiliar a acessar o conhecimento fonológico da criança acerca de elementos que estão ainda em desenvolvimento em seu sistema linguístico.

O Quadro 1 abaixo traz as diferentes estratégias de reparo observadas por Teixeira (1988), Lamprecht (1993), Miranda (1996), Ribas $(2002,2006)$ e Baesso (2009) na aquisição da sílaba CCV do PB. É interessante ressaltar que essas estratégias também foram atestadas por Greenlee (1974) em outras seis línguas: inglês, francês, estoniano, sérvio, esloveno e tcheco.

\begin{tabular}{|c|c|c|}
\hline Estratégia de reparo & Descrição & Exemplo \\
\hline Apagamento de CCV & Apagamento da sílaba contendo CCV & 'floresta' ['Es.te] \\
\hline Apagamento de $\mathrm{C}_{1}$ & Produção dos segmentos em $\mathrm{C}_{2} \mathrm{~V}$ & 'bicicleta' ['bi.le.te] \\
\hline Apagamento de $\mathrm{C}_{2}$ & Produção dos segmentos em $\mathrm{C}_{1} \mathrm{~V}$ & 'bruxa' ['bu. $\left.\int \mathrm{e}\right]$ \\
\hline Apagamento de $\mathrm{C}_{1}+\mathrm{C}_{2}$ & Produção apenas da vogal do CCV & 'blusa' ['u.ze] \\
\hline Substituição $\mathrm{C}_{1}$ & $\begin{array}{l}\text { Alteração de ponto de articulação, } \\
\text { modo ou vozeamento do segmento } \\
{\text { em } C_{1}}\end{array}$ & $\begin{array}{l}\text { "blusar ['plu.za] } \\
\text { 'blusar ['vlu.za] }\end{array}$ \\
\hline Substituição $\mathrm{C}_{2}$ & Alteração da líquida em $\mathrm{C}_{2}$ & 'braço’ ['bla.so] \\
\hline Metátese (cf. nota) & $\begin{array}{l}\text { Alteração da posição } \quad \mathrm{C}_{1} \mathrm{C}_{2} \text { : } \\
\mathrm{CCV}>>\mathrm{CVC}\end{array}$ & 'magro` ['ma.gor] \\
\hline Transposição & $\begin{array}{l}\text { Movimento da líquida à sílaba } \\
\text { adjacente }\end{array}$ & 'pedra` ['pre.de] \\
\hline
\end{tabular}

Revista Letras,

Curitiba, UFPR, n. 96, pp.255-286, jul./dez. 2017 ISSN 2236-0999 (versão eletrônica) 


\begin{tabular}{|c|c|c|}
\hline Movimento recíproco & $\begin{array}{l}\text { Permuta entre segmentos ou traços de } \\
\text { duas sílabas adjacentes }\end{array}$ & $\begin{array}{l}\text { ‘dragão` [gra'dãw] } \\
\text { 'cérebro` ['sє.be.lu] }\end{array}$ \\
\hline Coalescência & Assimilação de $[+\operatorname{cont} t]$ em $\mathrm{C}_{2}$ por $\mathrm{C}_{1}$ & 'trem ['sẽj] \\
\hline Epêntese vocálica & Adição de uma vogal entre $\mathrm{C}_{1}$ e $\mathrm{C}_{2}$ & 'trem' [te’rẽj] \\
\hline Inserção consonantal & Adição de uma posição $\mathrm{C}_{2}$ a um CV & 'pedra` ['pre.dre] \\
\hline
\end{tabular}

Quadro 1: Tipos de estratégia de reparo na aquisição CCV segundo Greenleee (1974), Teixeira (1988) e Ribas (2002, 2004). Alguns dos exemplos foram retirados de Ribas (2004, p. 154-156)

Miranda (1996) e Ribas (2002) observaram em seus estudos que a aplicação das estratégias de reparo tinha como alvo majoritariamente a modificação de sílabas com $\mathrm{C}_{1}$ coronal - que, em geral, sofriam um apagamento de seu segmento em $\mathrm{C}_{2}$. A variável ponto de articulação foi apontada como significativa à modificação das sílabas $\mathrm{C} / \mathrm{r} / \mathrm{V}$ nos testes estatísticos de ambas as autoras, sugerindo uma preferência pela produção de sílabas com $\mathrm{C}_{1}$ labial no $\mathrm{C} / \mathrm{r} / \mathrm{V}$, seguidas por dorsais. Em relação às sílabas C/l/V, Ribas (2002) verificou em seus dados a presença somente dos pontos de articulação labial e dorsal, que não apresentaram em sua produção uma preferência estaticamente significativa. Montenegro (2012) também observa significância do ponto de articulação na realização das sílabas $\mathrm{C} / \mathrm{r} / \mathrm{V}$ em seu estudo, havendo preferência por consoantes labiais $(/ \mathrm{p}, \mathrm{b}, \mathrm{f}, \mathrm{v} /)$. No entanto, diferentemente do observado em Miranda (1996) e Ribas (2002), a consoante /t/ também foi apontada como favorecedora à produção CCV nos dados de Montenegro (2012). A consoante /d/, por outro lado, foi apontada como a mais desfavorecedora nesse mesmo estudo, evidenciando uma possível diferença na produção dos segmentos dentro do grupo coronal. Interessantemente, quando alterando a variável dependente do estudo, de "produção CCV" para "redução CCV", Montenegro (2012) observa o favorecimento à redução do ataque complexo tanto pela consoante /d/ como pela consoante $/ \mathrm{t} /$, seguidas também da velar $/ \mathrm{k} /$. A coronal surda parece, assim, ter um status ambíguo entre o favorecimento e o desfavorecimento das produções CCV neste estudo.

Também se observam divergências na literatura relativamente à presença ou ausência de estágios intermediários na aquisição do CCV - estágios em que uma estratégia específica seria sistematicamente utilizada em reparo à produção CCV, num momento próximo à sua aquisição. Ribas (2002) afirma não haver estágios intermediários no preenchimento de $\mathrm{C}_{2}$ na aquisição do ataque ramificado, havendo passagem direta da produção reduzida do ataque complexo

3 Seguindo Teixeira (1988), Magalhães (2003) e Redmer (2007), diferenciaremos o processo referido como metátese na literatura em três fenômenos distintos. Consideramos como metátese, propriamente, o processo que altera a estrutura de $\mathrm{C}_{1} \mathrm{C}_{2} \mathrm{Va} \mathrm{C}_{1} \mathrm{VC}_{2}$, como em ['ma.gor] 'magro' e ['vi.dur] 'vidro', podendo haver também um movimento de $\mathrm{C}_{2}$ à sílaba adjacente ao CCV de origem, como em ['per.de] 'pedra' e ['kJr.be] 'cobra'; como transposição o movimento de $\mathrm{C}_{2}$ entre sílabas, porém sem alteração da estrutura silábica, como em [vri.do] 'vidro' e [kro.be] 'cobra'; e como movimentorecíproco a permuta entre os segmentos ou traços de $\mathrm{C}_{1}$ nas sílabas da palavra, como em ['kru.be] 'Pruga' e [gra'dãw] 'dragão'. 
A. TonI Estratégias de reparo ao ataque ramificado $\mathrm{CCV}$ na aquisição fonológica

$\mathrm{C}_{1} \mathrm{~V}$ à sua produção correta $\mathrm{CCV}$ - uma vez que, em seus dados, menos de 10\% das palavras sofreram estratégias de reparo diferentes da redução CCV, o que indicaria a ausência de um padrão de substituições sistemáticas da líquida ou da estrutura CCV. Por outro lado, Teixeira (1988) e Lamprecht (1993) apontam um desenvolvimento do tipo apagamento > substituição > produção no percurso de aquisição do ataque ramificado, com a existência de um estágio intermediário em que se observaria que o tepe /s/ de um CCV pode ser substituído pelo glide /j/ ou por uma aproximante e pela líquida lateral /1/ antes de ser corretamente produzido como não-lateral, e mesmo a lateral /// também poderia ser substituída pelo glide /j/ antes de sua completa estabilização. Paralelamente, nesses estágios a estrutura $\mathrm{CCV}$ poderia também ser modificada pela criança por meio de epênteses e metáteses, visando desfazer a sequência $\mathrm{C}_{1} \mathrm{C}_{2}$. As autoras pontuam, contudo, que esses percursos - quer em relação aos segmentos líquidos, quer em relação à estrutura CCV - não seriam obrigatórios na aquisição fonológica. Segundo Teixeira (1988), poderia ainda existir uma última etapa pré-aquisição, em que o ataque ramificado, apesar de ser produzido corretamente com um tepe em $\mathrm{C}_{2}$, sofreria transposições sistemáticas a fim de ser produzido como o elemento inicial da palavra, como em [dre'gaw] 'degrau'. Essa estratégia pode ter sua motivação atribuída, segundo a autora, ao aspecto destacado da posição inicial da palavra na prosódia da fala, sendo consistentemente considerada favorecedora em estudos fonoaudiológicos e aquisicionistas (LAMPRECHT et al., 2004). No entanto, em função de exemplos de transposição em direção oposta, como [da'grã w̃] 'dragão' (REDMER, 2007) e [ta'tror] 'trator' (RIBAS, 2002), é possível conjecturar se essas transposições teriam efetivamente como alvo a posição inicial da palavra ou se buscariam, talvez, a sílaba tônica, conforme observado por Miranda (1996) - ou, ainda, se buscariam combinações segmentais CCV específicas ou "facilitadoras", conforme Ribas (2002).

É interessante observar, ainda, que o processo de epêntese que ocorre na aquisição CCV em PB apresenta propriedades diferentes daquele descrito por Collischonn (1999) em relação à silabificação. Nesta última, encontros consonantais como os de 'Knorr', 'amnésia', 'Phillips', 'spa' e 'tungstênio' são desfeitos por meio da inserção de uma vogal default, [I], à direita ou à esquerda do segmento não associado ao nó silábico, a depender do modo de articulação desse segmento - se oclusivo ou sibilante. Assim, são geradas as formas [kı'nગr], [a.mi'nz.zja], ['fi.lı.pıs], [s'pa] e [tuy.gis'te.niw]. Na epêntese que ocorre na fala infantil para desfazer a sequência $\mathrm{C}_{1} \mathrm{C}_{2}$ de $\mathrm{CCV}$, no entanto, a vogal a emergir não é a vogal default [I], mas uma cópia da vogal no núcleo da sílaba CCV, por vezes enfraquecida mas de mesmos valores de ponto, altura e arredondamento: 'prato' ['p'ra.to], 'blusa' ['blu.ze], 'grito' [g'ri.to], 'pronto' ['po rõ.to]. Essa vogal, denominada vogal auxiliar, vogal de apoio ou svarabhakti vowel, é comum também nas produções adultas de algumas línguas, como o Espanhol e suas variantes (ALONSO, 1953; BRADLEY e SCHMEISER, 2003; SCHMEISER, 2009), e

Revista Letras,

Curitiba, UFPR, n. 96, pp.255-286,

jul./dez. 2017 ISSN 2236-0999 (versão eletrônica) 
mesmo no Português Brasileiro (SILVEIRA e SEARA, 2008; NISHIDA, 2009), não sendo característica apenas da fala infantil. Conforme Bradley \& Schmeiser (2003, p. 2), exemplos contendo uma vogal de apoio podem ser observados no Espanhol em palavras como 'pronto' [ $\left.\mathrm{p}^{ } \mathrm{r}\right]$ pronto, 'fresco' [ $\left.\mathrm{f}^{\circledR} \mathrm{r}\right]$ fresco, 'otro'

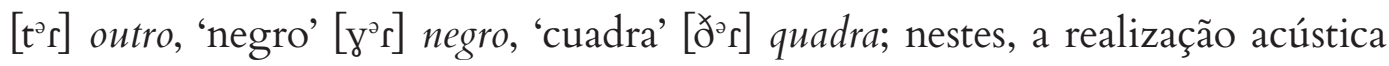
da vogal de apoio pode se dar de três modos possíveis, a depender do grau de sobreposição dos gestos articulatórios de $/ \mathrm{C} / \mathrm{e} / \mathrm{r} /$, tal como representado na Figura 1: como uma cópia fiel da vogal núcleo da sílaba, [CvrV] (Figura 1a), cuja vogal inserida pode apresentar duração por vezes maior que a do tepe; como um fragmento vocálico de curta duração, como em [ $\mathrm{C}^{\mathrm{r}} \mathrm{rV}$ ] (Figura 1b); ou com total sobreposição entre a vogal de apoio e o tepe, gerando o segmento aproximante $[\mathrm{I}]$, como em [CIV] (Figura 1c):
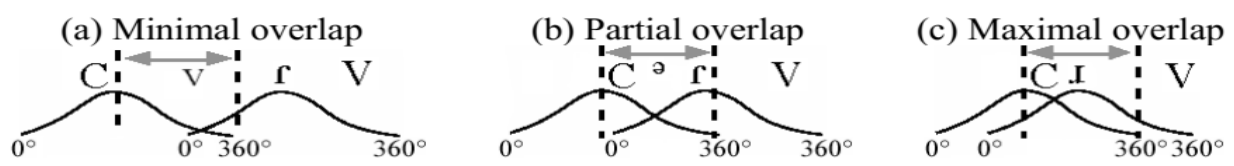

Figura 1 - Graus de sobreposição da vogal de apoio em CCV nas variantes espanholas (Fonte: Bradley e Schmeiser (2003, p. 5)).

Relativamente ao Português Brasileiro, Silveira e Seara (2008) observam a produção de vogais de apoio em $96 \%$ das realizações de ataques ramificados CCV em seu corpus, em exemplos como 'brado', 'brisa', 'bruxa', 'traça', 'tripa', 'truque', conforme ilustrado na Figura 2a. Distintamente do observado nas variantes espanholas, em $\mathrm{PB}$ não se verificam produções $[\mathrm{CıV}]$ ao $\mathrm{CCV}$; a natureza e qualidade da vogal de apoio observada - se [CvrV] ou [CərV] - é, entretanto, discutida: questiona-se se esta porção vocálica seria o início da vogal núcleo, entrecortado pelo tepe (NISHIDA, 2009) ou se seria uma vogal central derivada do núcleo CCV (SILVEIRA e SEARA, 2008). Acusticamente, verificase em ambos os estudos que a vogal de apoio se delineia num espaço vocálico mais restrito e centralizado se comparado à vogal núcleo, como trazido pela Figura 2b.

$2 \mathrm{a}$

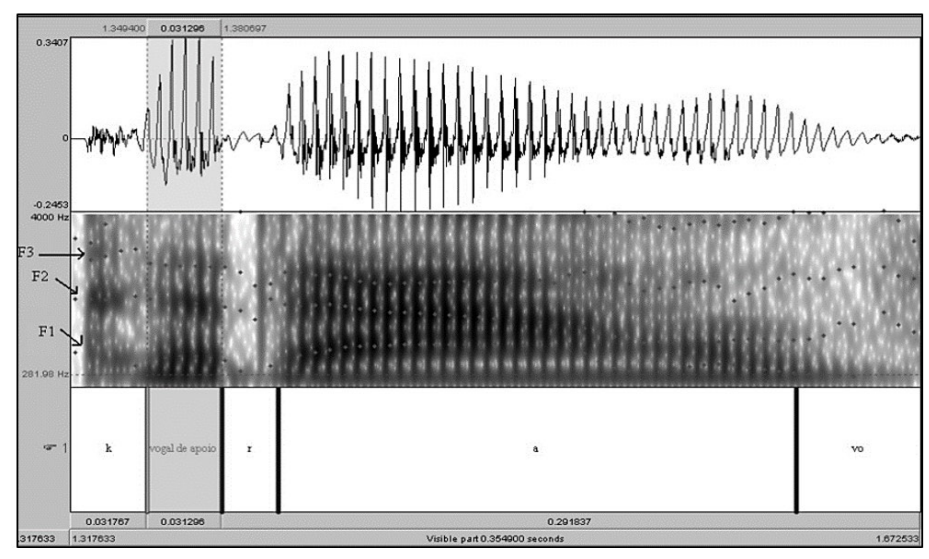

$2 b$

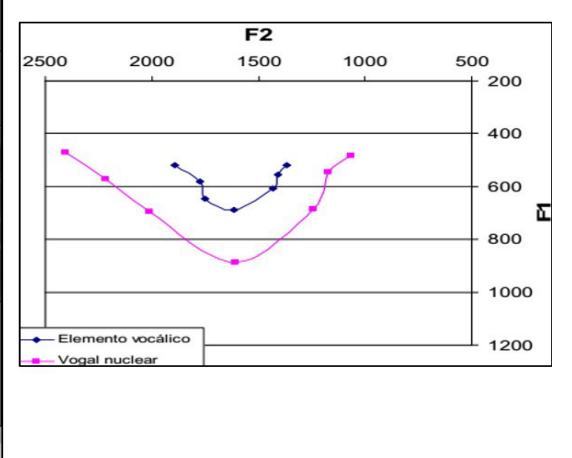

Figura 2a - Vogal de apoio na palavra "cravo"

Figura $2 \mathrm{~b}$ - Médias de f1 e f2 dos elementos vocálicos e vogais nucleares de sílabas (Fonte: Silveira e SeAra (2008, p. 38); Nishida (2009, p. 131)) 
A. TonI Estratégias de reparo ao ataque ramificado $\mathrm{CCV}$ na aquisição fonológica

Tendo em vista a presença das vogais de apoio em CCV também em fala adulta, observa-se que o tipo de vogal emergida entre $\mathrm{C}_{1}$ e $\mathrm{C}_{2}$ na aquisição do CCV em PB, se default ([I]) ou se derivada da vogal-núcleo da sílaba (svarabhakti), poderia também constituir uma evidência à observação do desenvolvimento da ramificação do ataque complexo na fala infantil, apontando para a ligação (ou não) do segmento líquido ao nó silábico de ataque a depender do tipo de vogal interveniente produzido pela criança. Vale notar, igualmente, que também a taxa de aplicação do processo de epêntese na silabificação e na aquisição CCV são diferentes: segundo Collischonn (1999), a epêntese seria o "mecanismo de salvamento" prioritário na silabificação, evitando o apagamento dos elementos não associados ao nó silábico (stray erasure); já na aquisição CCV observa-se uma preferência pelo apagamento, e não pela epêntese, que apresentou taxa de aplicação de apenas $0,3 \%$ nos dados de Ribas (2002), tanto para C/s/V quanto para C/l/V.

\section{Metodologia}

Os dados utilizados neste trabalho procedem da pesquisa de mestrado de Toni (2016), aprovados pelo Comitê de Ética em Pesquisa com Seres Humanos sob o CAAE 43086214.4.0000.5498.

Foram analisadas gravações de fala de 49 crianças, de idades entre 2;4 e 5;10 anos, que pertenciam a duas séries ou módulos pré-escolares consecutivos, sendo 24 meninas e 25 meninos. O experimento consistiu de tarefas de repetição de palavras contendo contextos de ataque ramificado $\mathrm{CCV}$, em que $\mathrm{C}_{1}$ compunhase pelas plosivas /p, t, k, b, d, g/, $\mathrm{C}_{2}$ pelas líquidas /, , / e $\mathrm{V}$ pelas vogais /a/, /i/ e $/ \mathrm{o}, \mathrm{u} /$. Um total de 52 alvos CCV foram apresentados às crianças, consistindo de nomes comuns ao vocabulário infantil (objetos, animais, personagens, etc.) e nomes inventados (como 'Tlaco', 'Blico', 'Croco', 'Graco'). A necessidade de utilizar logatomas deu-se para atender à produção de contextos segmentais raros ou ausentes na língua, como / $\mathrm{t}$, dl/, e também à produção de contextos em que não foi possível encontrar itens lexicais passíveis de ilustração no rol de palavras pertencentes ao léxico infantil. Todas as palavras selecionadas apresentavam molde prosódico do tipo ['CCV.CV], com as sílabas-alvo localizadas na posição tônica da palavra. A escolha por sílabas tônicas e iniciais como portadoras das estruturas-alvo do estudo justifica-se por denotar um contexto experimental fonologicamente mais conservador, de proeminência prosódica (LAMPRECHT et al., 2004). O intuito, com isso, era observar de que forma as estruturas CCV seriam manipuladas pela criança num contexto linguisticamente desfavorável a essas modificações do input. Deste modo, a maior ocorrência de estratégias de reparo em determinados contextos segmentais ou grupos de desenvolvimento não poderia ser atribuída, por exemplo, a um relaxamento articulatório

Revista Letras,

Curitiba, UFPR, n. 96, pp.255-286,

jul./dez. 2017 ISSN 2236-0999 (versão eletrônica) 
causado pelo contexto prosódico ou ao próprio caráter perceptualmente menos proeminente da posição dos alvos em análise - pelo contrário, seria observado que tais interações entre o input e a gramática infantil ocorreriam apesar de seu desfavorecimento pelo contexto de alta proeminência prosódica.

A opção por utilizar tarefas de repetição em detrimento de atividades de nomeação espontânea deu-se por três motivos: i) não seria possível elicitar os logatomas utilizados na pesquisa por meio da nomeação espontânea; ii) mesmo os estímulos passíveis de ilustração dependeriam do reconhecimento lexical da criança, além de estarem também sujeitos à variedade de itens lexicais a que se poderia atribuir uma mesma figura - por exemplo, na ilustração da palavra 'classe', que era o primeiro estímulo a ocorrer no teste, algumas crianças espontaneamente nomearam a figura com os termos 'escola', 'estudar', 'lendo', eliminando o contexto de ataque CCV; iii) em testes de nomeação espontânea não é possível distinguir se a substituição de uma palavra por outra poderia ser atribuída a uma estratégia de evitação de determinados contextos linguísticos ou se seria devida simplesmente a um lapso no reconhecimento ou na recuperação lexical de um item vocabular (MONTENEGRO, 2012). Em vista disso, optamos pela repetição como forma de elicitação dos dados, assumindo, tal como Scarpa (1984) e Crain e Thornton (2000), que a imitação não se comportaria como uma cópia ou repetição mecânica de um modelo; as tarefas de repetição na fala infantil se manifestariam, em verdade, como "uma reconstrução do estímulo", cuja realização também seria dependente da gramática infantil. Ressaltamos, ainda, que por criar uma situação discursiva desfavorável à evitação, as tarefas de repetição se mostram como um bom método de "elicitação" de estratégias de reparo.

Os dados coletados foram verificados acusticamente por meio do Software Praat (versão 5.4.06, view range entre $0-9000 \mathrm{~Hz}$, window lenght de banda larga). Talverificaçãofoiutilizada napesquisaafim deembasara categorização da produção silábica realizada pelos sujeitos, considerando também a possível observação de contrastes encobertos - descritos por Scobbie (1998) como mismatches entre a produção articulada pela criança e a produção detectada oitivamente pelo adulto. Desse modo, a observação de elementos segmentais intervenientes entre a oclusiva e a vogal núcleo da sílaba CCV foi também considerada à categorização das produções infantis, embora nem sempre esses elementos pudessem ser oitivamente discriminados.

As estratégias de reparo à estrutura CCV foram categorizadas conforme a classificação do Quadro 1 acima. Nos contextos elicitados, procuramos observar se os seguintes fatores estariam influenciando a produção dos alvos de ataque ramificado: 1) Tipo de líquida: /l/ ou /r/; 2) Classe da oclusiva: labial, coronal, dorsal; 3) Tipo de oclusiva: /b, d, g, p, t, k/; 4) Tipo de Vogal: /i/ ou diferente de /i/ (/u/, /o/, /a/); 5) Tipo de palavra: existente ou logatoma (pseudo-palavra). Ao controlar a qualidade da líquida a ocupar a posição $\mathrm{C}_{2}$ e a qualidade e 
A. TONI

Estratégias de reparo ao ataque ramificado $\mathrm{CCV}$ na aquisição fonológica classe articulatória da consoante a ocupar a posição $\mathrm{C}_{1}$ do CCV nos estímulos experimentais, buscamos analisar a influência que tais propriedades fonológicas infligiriam sobre a produção do ataque ramificado na fala da criança, procurando, com isso, observar possíveis efeitos dos filtros segmentais sobre a realização do molde silábico CCV. Por sua vez, controlar a qualidade no núcleo vocálico CCV em segmentos /i/ ou diferente de /i/ teve como objetivo testar se o contexto de desfavorecimento coronal observado por Miranda (1996) e Ribas (2002) seria também aplicável às vogais núcleo das sílabas CCV. Por fim, monitorar o tipo de palavra a constituir o estímulo experimental, se inventada ou existente na língua, dispõe-se a verificar se itens lexicais desconhecidos pela criança poderiam ser alvos mais visados às manipulações do ataque ramificado - ou se, ao contrário, tais itens apresentariam mesmo padrão de realização que os itens lexicais conhecidos na fala infantil.

Por fim, visando detectar possíveis variações no padrão de aplicação de estratégias de reparo ao longo do percurso de aquisição CCV, foi feita uma divisão dos dados infantis em grupos de acordo com o percentual de realizações-alvo do ataque ramificado. Esta divisão se fez necessária devido à observação de que crianças de uma mesma faixa etária apresentavam taxas de produção CCV bastante distintas - observação corroborada também por um estudo naturalístico em Toni (2016), além de estudos fonoaudiólogicos como Lamprecht et al. (2004). Enquanto o fator Idade admitiria a comparação de diferentes momentos de desenvolvimento silábico desde que estes fossem referentes a crianças de uma mesma idade, o percentual de produções-alvo CCV (tal como no modelo adulto) viabiliza a comparação entre crianças de mesmos estágios de desenvolvimento silábico. Desta forma, os dados da pesquisa foram divididos em cinco grupos percentuais de realização-alvo da ramificação de ataque, conforme o Quadro 2 - em que G1 corresponde à ausência (ou reprodução mecânica e esporádica) do CCV; G2 corresponde a uma produção incipiente, abaixo da metade do total de produções; G3 corresponde a um total de produções-alvo em torno da metade dos dados; G4 corresponde a produções ainda não consideradas estabilizadas, mas já recorrentes, acima da metade do total de dados; e G5 corresponde à aquisição do ataque ramificado (de acordo com o percentual seguido por Lamprecht et al., 2004).

\begin{tabular}{|c|c|c|c|c|c|}
\hline Grupo & G1 & G2 & G3 & G4 & G5 \\
\hline \% CCV-alvo & 0 a $5 \%$ & 6 a $40 \%$ & 41 a $60 \%$ & 61 a $75 \%$ & acima de $76 \%$ \\
\hline
\end{tabular}

Quadro 2 - Divisão das produções infantis em faixas pelo percentual de realizações-alvo $\mathrm{CCV}$

Para classificar os dados infantis, os percentuais foram calculados desconsiderando-se a produção (correta ou não) das combinações /tl, dl/, pois consideramos que contabilizar também a produção destes alvos raros no input da criança poderia levar à categorização incorreta de sujeitos cuja produção-alvo
Revista Letras,

Curitiba, UFPR, n. 96, pp.255-286, jul./dez. 2017 ISSN 2236-0999 (versão eletrônica) 
CCV mostra-se reduzida somente nestes contextos - possivelmente equiparandoos a sujeitos cujas reduções CCV abrangeriam também as combinações fonotáticas produtivas na língua alvo.

Conforme a Tabela 1 a seguir, das 49 crianças participantes do estudo, 15 foram classificadas dentro do grupo G1, 7 em G2, 5 em G3, 13 em G4 e 9 em G5. Salientamos o salto na quantidade de realizações-alvo observadas na passagem entre G1 e G2, de no máximo 2 no primeiro grupo para um mínimo de 10 no segundo grupo, padrão que corrobora a consideração de produções CCV como "mecânicas" ou não-analisadas em G1 (que se referiam, majoritariamente, aos logatomas que nomeavam as figuras em feltro, como 'Blico' (criança 7), 'Glico' (criança 15) e 'Tlaco' (criança 9)). Nota-se, também, uma grande variabilidade na distribuição etária dos grupos: na faixa de três anos é possível observar crianças dentro dos grupos G1, G2 e G3; da mesma forma, na faixa de 4 anos observa-se crianças ainda em G1 e outras já em G5. Crianças de 5 anos distribuem-se entre os grupos G3 e G5; nota-se uniformidade apenas nas crianças de 2 anos, todas pertencentes ao G1.

\section{Resultados}

Inicialmente, destacamos que, embora o experimento contivesse 52 estímulos CCV, algumas crianças produziram menos palavras do que o esperado (quando, por exemplo, se recusavam a dizer 'Pluto' e diziam 'au-au'), enquanto, por outro lado, houve casos em que a criança produziu uma palavra mais de uma vez. Com isso, o total de palavras produzidas no experimento foi de 3.062 - 1261 produções-alvo, 887 reduções CCV > $C_{1} V$ e 914 outras estratégias de reparo (contadas separadamente em relação à redução CCV). A Tabela 1 abaixo apresenta a classificação dos dados analisados no estudo, organizado por grupos, informantes e tipos de resposta aos estímulos. O percentual de produções-alvo em que não houve consideração dos contextos /tl, $\mathrm{dl} /$, base para a divisão em grupos, é apresentado na coluna 3; 4 já nas colunas 4, 5, 6 e 7 apresentam-se os dados incluindo os contextos $/ \mathrm{tl}, \mathrm{dl} /$, referentes, respectivamente, às produçõesalvo, reduções CCV, estratégias de reparo aplicadas a CCV e, por fim, o total de dados coletados por sujeito.

4 O percentual apresentado é referente ao total de dados produzidos excluindo-se os alvos /tl, dl/, sendo, portanto, diferente do total apresentado na coluna 7. Para verificar o total de produções sem /tl, d/, cf. Toni (2016). 


\begin{tabular}{|c|c|c|c|c|c|c|c|}
\hline Grupo & Sujeito & Idade & $\begin{array}{l}\text { Produção CCV } \\
\text { (sem/tl, dl/) }\end{array}$ & $\begin{array}{l}\text { Produção CCV } \\
\text { (com /tll, dl/) }\end{array}$ & $\begin{array}{l}\mathrm{CCV}>>\mathrm{C}_{1} \mathrm{~V} \\
(\mathrm{com} / \mathrm{t} \mathrm{d}, \mathrm{dl})\end{array}$ & $\begin{array}{l}\text { Reparos } \\
(\text { com /tl, dl/) }\end{array}$ & $\begin{array}{l}\text { Total } \\
\text { (com } \\
\text { /tll, dl/) }\end{array}$ \\
\hline \multirow{16}{*}{ G1 } & 1 & $2 ; 04.09$ & $0(0 \%)$ & $0(0 \%)$ & $57(73,08 \%)$ & $21(26,92 \%)$ & 78 \\
\hline & 2 & $2 ; 04.15$ & $0(0 \%)$ & $0(0 \%)$ & $54(69,23 \%)$ & $24(30,77 \%)$ & 78 \\
\hline & 3 & $2 ; 04.22$ & $0(0 \%)$ & $0(0 \%)$ & $49(70 \%)$ & $21(30 \%)$ & 70 \\
\hline & 4 & $2 ; 06.04$ & $0(0 \%)$ & $0(0 \%)$ & $36(64,29 \%)$ & $20(35,71 \%)$ & 56 \\
\hline & 5 & $2 ; 07.12$ & $0(0 \%)$ & $0(0 \%)$ & $50(87,72 \%)$ & $7(12,28 \%)$ & 57 \\
\hline & 7 & $3 ; 00.03$ & $0(0 \%)$ & $0(0 \%)$ & $40(75,47 \%)$ & $13(24,53 \%)$ & 53 \\
\hline & 8 & $3 ; 01.25$ & $0(0 \%)$ & $1(2,13 \%)$ & $19(61,29 \%)$ & $11(35,48 \%)$ & 31 \\
\hline & 10 & $3 ; 03.28$ & $0(0 \%)$ & $0(0 \%)$ & $22(59,46 \%)$ & $15(40,54 \%)$ & 37 \\
\hline & 13 & $3 ; 06.07$ & $0(0 \%)$ & $1(2,13 \%)$ & $44(77,19 \%)$ & $13(22,81 \%)$ & 57 \\
\hline & 15 & $3 ; 08.25$ & $0(0 \%)$ & $0(0 \%)$ & $45(80,36 \%)$ & $11(19,64 \%)$ & 56 \\
\hline & 14 & $3 ; 07.00$ & $1(1,79 \%)$ & $1(1,47 \%)$ & $33(48,53 \%)$ & $34(50 \%)$ & 68 \\
\hline & 9 & $3 ; 02.25$ & $1(2,04 \%)$ & $1(1,49 \%)$ & $57(85,07 \%)$ & $9(13,43 \%)$ & 67 \\
\hline & 18 & $3 ; 10.20$ & $1(2,04 \%)$ & $1(1,59 \%)$ & $47(74,6 \%)$ & $15(23,81 \%)$ & 63 \\
\hline & 19 & $3 ; 10.28$ & $1(2,17 \%)$ & $1(1,69 \%)$ & $46(77,97 \%)$ & $12(20,34 \%)$ & 59 \\
\hline & 6 & $3 ; 00.00$ & $2(4,55 \%)$ & $2(3,7 \%)$ & $25(46,3 \%)$ & $27(50 \%)$ & 54 \\
\hline & \multicolumn{3}{|l|}{ Soma } & $7(0,79 \%)$ & $624(70,59 \%)$ & $253(28,62 \%)$ & 884 \\
\hline \multirow{8}{*}{ G2 } & 16 & 3;09.05 & $10(20 \%)$ & $12(18,75 \%)$ & $34(53,12 \%)$ & $18(28,13 \%)$ & 64 \\
\hline & 17 & $3 ; 09.10$ & $11(21,15 \%)$ & $12(22,64 \%)$ & $18(33,96 \%)$ & $23(43,4 \%)$ & 53 \\
\hline & 20 & $3 ; 11.18$ & $16(29,09 \%)$ & $17(30,36 \%)$ & $12(21,43 \%)$ & $27(48,21 \%)$ & 56 \\
\hline & 25 & $4 ; 05.01$ & $16(34,78 \%)$ & $20(31,75 \%)$ & $15(23,81 \%)$ & $28(44,44 \%)$ & 63 \\
\hline & 11 & $3 ; 04.15$ & $20(35,20 \%)$ & $21(27,63 \%)$ & $8(10,53 \%)$ & $47(61,84 \%)$ & 76 \\
\hline & 12 & 3;05.09 & $16(37,21 \%)$ & $19(31,67 \%)$ & $27(45 \%)$ & $14(23,33 \%)$ & 60 \\
\hline & 21 & 4;00.09 & $21(38,89 \%)$ & $25(35,71 \%)$ & $4(5,71 \%)$ & $41(58,57 \%)$ & 70 \\
\hline & \multicolumn{3}{|l|}{ Soma } & $126(28,5 \%)$ & $118(26,69 \%)$ & $198(44,8 \%)$ & 442 \\
\hline \multirow{6}{*}{ G3 } & 28 & $4 ; 07.07$ & $31(51,67 \%)$ & $39(52 \%)$ & $1(1,33 \%)$ & $35(46,67 \%)$ & 75 \\
\hline & 23 & $4 ; 02.16$ & $28(54,90 \%)$ & $31(44,29 \%)$ & $4(5,71 \%)$ & $35(50 \%)$ & 70 \\
\hline & 26 & $4 ; 05.29$ & $34(55,74 \%)$ & $34(44,16 \%)$ & $3(3,89 \%)$ & $40(51,95 \%)$ & 77 \\
\hline & 33 & $4 ; 10.14$ & $24(58,54 \%)$ & $26(50 \%)$ & $2(3,85 \%)$ & $24(46,15 \%)$ & 52 \\
\hline & 29 & $4 ; 07.21$ & $27(60 \%)$ & $34(60,71 \%)$ & $8(14,29 \%)$ & $14(25 \%)$ & 56 \\
\hline & \multicolumn{3}{|l|}{ Soma } & $164(49,7 \%)$ & $18(5,45 \%)$ & $148(44,84 \%)$ & 330 \\
\hline
\end{tabular}




\begin{tabular}{|c|c|c|c|c|c|c|c|}
\hline \multirow{14}{*}{ G4 } & 32 & $4 ; 10.10$ & $27(61,36 \%)$ & $33(58,93 \%)$ & $4(7,14 \%)$ & $19(33,93 \%)$ & 56 \\
\hline & 27 & $4 ; 07.06$ & $30(62,50 \%)$ & $36(59,02 \%)$ & $10(16,39 \%)$ & $15(24,59 \%)$ & 61 \\
\hline & 34 & $4 ; 11.11$ & $39(65 \%)$ & $46(64,79 \%)$ & $12(16,9 \%)$ & $13(18,31 \%)$ & 71 \\
\hline & 35 & $4 ; 11.29$ & $28(66,67 \%)$ & $30(56,6 \%)$ & $3(5,66 \%)$ & $20(34,74 \%)$ & 53 \\
\hline & 24 & $4 ; 03.18$ & $31(67,39 \%)$ & $35(57,38 \%)$ & $7(11,48 \%)$ & $19(31,15 \%)$ & 61 \\
\hline & 22 & $4 ; 01.02$ & $30(68,18 \%)$ & $37(66,07 \%)$ & $3(5,36 \%)$ & $16(28,57 \%)$ & 56 \\
\hline & 31 & $4 ; 09.26$ & $45(71,43 \%)$ & $47(55,95 \%)$ & $17(20,24 \%)$ & $20(23,81 \%)$ & 84 \\
\hline & 30 & $4 ; 09.12$ & $40(72,73 \%)$ & $51(71,83 \%)$ & $6(8,45 \%)$ & $14(19,72 \%)$ & 71 \\
\hline & 47 & $5 ; 09.15$ & $35(72,92 \%)$ & $40(66,67 \%)$ & $13(21,67 \%)$ & $7(11,67 \%)$ & 60 \\
\hline & 48 & $4 ; 09.30$ & $41(73,21 \%)$ & $47(71,21 \%)$ & $1(1,52 \%)$ & $18(27,27 \%)$ & 66 \\
\hline & 43 & $5 ; 06.28$ & $38(74,51 \%)$ & $48(67,61 \%)$ & $6(8,45 \%)$ & $17(23,94 \%)$ & 71 \\
\hline & 42 & $5 ; 05.20$ & $30(75 \%)$ & $31(70,45 \%)$ & $2(4,54 \%)$ & $11(25 \%)$ & 44 \\
\hline & 49 & $5 ; 10.01$ & $42(75 \%)$ & $44(62,86 \%)$ & $5(7,14 \%)$ & $21(30 \%)$ & 70 \\
\hline & \multicolumn{3}{|c|}{ Soma } & $525(63,71 \%)$ & $89(10,8 \%)$ & $210(25,49 \%)$ & 824 \\
\hline \multirow{10}{*}{ G5 } & 41 & $5 ; 05.12$ & $35(77,78 \%)$ & $38(63,33 \%)$ & $2(3,33 \%)$ & $20(33,33 \%)$ & 60 \\
\hline & 40 & $5 ; 05.04$ & $37(80,43 \%)$ & $40(67,8 \%)$ & $7(11,86 \%)$ & $12(20,34 \%)$ & 59 \\
\hline & 44 & $5 ; 08.16$ & $45(81,82 \%)$ & $50(70,42 \%)$ & $5(7,04 \%)$ & $16(22,54 \%)$ & 71 \\
\hline & 37 & 5;03.16 & $50(84,75 \%)$ & $56(74,67 \%)$ & $4(5,33 \%)$ & $15(20 \%)$ & 75 \\
\hline & 36 & $5 ; 02.19$ & $40(86,96 \%)$ & $49(80,33 \%)$ & $4(6,56 \%)$ & $8(13,11 \%)$ & 61 \\
\hline & 39 & $5 ; 05.03$ & $58(87,88 \%)$ & $66(82,50 \%)$ & $5(6,25 \%)$ & $9(11,25 \%)$ & 80 \\
\hline & 46 & 5;09.09 & $37(88,10 \%)$ & $41(77,36 \%)$ & $2(3,77 \%)$ & $10(18,67 \%)$ & 53 \\
\hline & 45 & $5 ; 08.29$ & $42(89,36 \%)$ & $51(85 \%)$ & $3(5 \%)$ & $6(10 \%)$ & 60 \\
\hline & 38 & $5 ; 04.26$ & $46(92 \%)$ & $50(75,76 \%)$ & $5(7,58 \%)$ & $11(16,67 \%)$ & 66 \\
\hline & \multicolumn{3}{|c|}{ Soma } & $441(75,38 \%)$ & $37(6,33 \%)$ & $107(18,29 \%)$ & 585 \\
\hline
\end{tabular}

Tabela 1: Total de realizações-alvo, reduções CCV e estratégias de reparo por informante

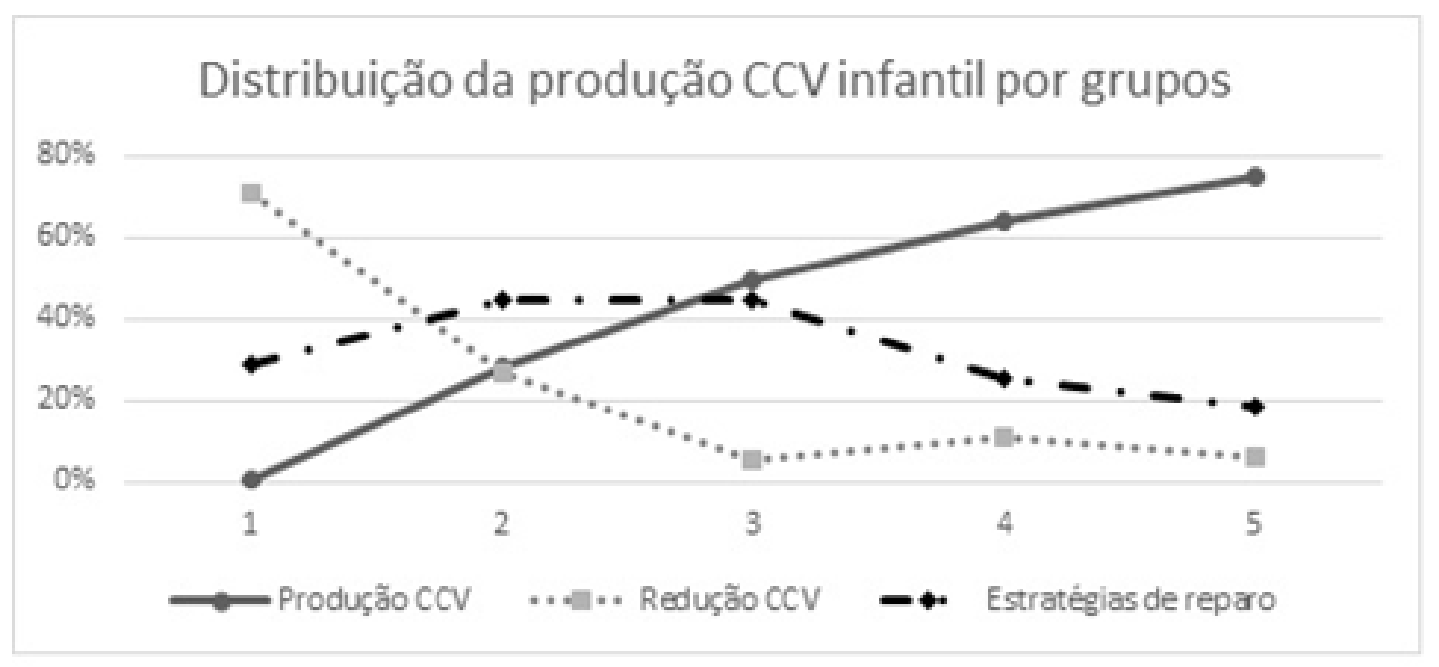

Gráfico 1: Distribuição das produções CCV por tipo de resposta ao estímulo

Observa-se na Tabela 1 acima que, enquanto no Grupo 1 há uma prevalência à Redução $\mathrm{C}_{1} \mathrm{~V}$ sobre as Produções-alvo e manipulações da sílaba $\mathrm{CCV}$, no Grupo 2 houve maior produção da categoria Estratégias de Reparo 
A. TONI Estratégias de reparo ao ataque ramificado $\mathrm{CCV}$ na aquisição fonológica em relação às demais - diferentemente do observado em Miranda (1996) e Ribas (2002). O Grupo 3 apresenta um equilíbrio entre Produções-alvo e Estratégias de Reparo, com menor número de Reduções CCV a C 1 V. Já nos Grupos 4 e 5 tem-se maior proporção de Produções-alvo, seguidas das Estratégias de Reparo e, por fim, da Redução CCV a C 1 V. O Gráfico 1 ilustra como essas estratégias vão mudando quantitativamente ao longo dos Grupos 1-5.

Relativamente aos fatores de influência às estratégias de reparo, um teste de proporções com intervalo de 95\% de confiança e significância a 5\% ( $<<0,05)$ foi conduzido5 visando comparar, para cada grupo, se a distribuição do tipo de resposta Estratégia de Reparo variaria entre os tipos de variáveis - para, assim, observar possíveis motivações contextuais às alterações silábicas e segmentais aplicadas pela criança aos estímulos experimentais.6 Na Tabela 2 abaixo listamse os p-valores obtidos às variáveis listadas na seção Metodologia, por grupos. Os valores em cinza representam os fatores apontados como estatisticamente significativos nos dados.

\begin{tabular}{|l|l|l|l|l|l|}
\hline Estratégias de reparo & G1 & G2 & G3 & G4 & G5 \\
\hline Variável & p-valor & p-valor & p-valor & p-valor & p-valor \\
\hline Tipo de líquida & 0.007357 & 0.226 & 0.001644 & 0.05484 & $3.347 \mathrm{e}-08$ \\
\hline Classe da oclusiva & $2.919 \mathrm{e}-06$ & 0.5886 & 0.1257 & $3.36 \mathrm{e}-05$ & $1.868 \mathrm{e}-07$ \\
\hline Tipo de oclusiva & $2.091 \mathrm{e}-08$ & 0.4798 & 0.006401 & $2.037 \mathrm{e}-11$ & $9.068 \mathrm{e}-09$ \\
\hline Tipo de vogal & 0.9976 & 0.5635 & 0.3945 & 0.6411 & 0.1296 \\
\hline Tipo de palavra & $9.468 \mathrm{e}-08$ & 0.0006346 & 0.004587 & $7.179 \mathrm{e}-06$ & $1.275 \mathrm{e}-08$ \\
\hline
\end{tabular}

Tabela 2: Valores de $\mathrm{p}$ referentes às variáveis estatísticas investigadas

Nota-se na Tabela 2 que o fator Tipo de palavra foi apontado como estatisticamente significativo à aplicação de estratégias em reparo à sílaba CCV em todos os grupos analisados na pesquisa: os logatomas apresentaram-se como um fator favorável à manipulação do ataque ramificado. Além deste, o Tipo de oclusiva também se mostrou um fator influente em todos os grupos, à exceção de G2: nos Grupos 1, 3, 4 e 5 percebe-se que sílabas CCV iniciadas pela oclusiva /d/ são significativamente mais visadas pelas manipulações infantis. Relativamente à Classe da oclusiva, tem-se o ponto [labial] como o menos propenso a sofrer estratégias de reparo nos Grupos 1, 4 e 5; nesses dois últimos, salientamos que a classe [coronal] estabelece-se como significativamente mais propensa a ser manipulada, tal como obtido também nos estudos de Miranda (1996) e Ribas (2002). No fator Tipo de líquida, por sua vez, que apresentou significância estatística nos Grupos 1, 3 e 5, o segmento lateral mantém-se como

5 O tratamento estatístico aplicado aos dados trazidos adiante foi conduzido no software R pelo mestre em Estatística Luís Iván Ortiz Valéncia, registrado sob o CONRE2 9652.

6 O mesmo teste também foi aplicado para os demais tipos de resposta: Produção-alvo e Redução CCV, separadamente. Para acessar seus resultados e as proporções de cada variante das variáveis aqui apresentadas, conferir Toni (2016).
Revista Letras,

Curitiba, UFPR, n. 96, pp.255-286, jul./dez. 2017 ISSN 2236-0999 (versão eletrônica) 
significativamente mais propenso a sofrer estratégias de reparo em comparação ao tepe. Por fim, destaca-se que o Tipo de vogal não apresentou significância estatística ao uso de estratégias de reparo em nenhum dos grupos analisados na pesquisa.

Já em relação à quantidade e natureza das estratégias de reparo, temse na Tabela 3 abaixo o total de modificações silábicas e segmentais coletadas no corpus da pesquisa. Dado que numa mesma sílaba diferentes estratégias de reparo poderiam se aplicar - como, por exemplo, nas produções 'Dlico' [bi'li. ko] (Informante 10), em que houve Substituição $C_{1}$ e Epêntese vocálica, ou em 'Drica' ['bix.ke] (Informante 12), em que houve Substituição $\mathrm{C}_{1}$, Substituição $\mathrm{C}_{2}$ e Metátese -, a soma das quantidades na Tabela 3 (e nas tabelas adiante) é maior que o total observado na coluna Estratégias de Reparo na Tabela 1, que se refere ao total de sílabas manipuladas pela criança - e não ao total de processos de manipulação.

\begin{tabular}{|c|c|c|c|c|c|c|c|c|c|c|}
\hline \multirow{3}{*}{$\begin{array}{l}\begin{array}{l}\text { Estratégias de } \\
\text { reparo }\end{array} \\
\text { Substituição } \\
\mathrm{C}_{1}\end{array}$} & \multicolumn{10}{|c|}{ Ocorrências } \\
\hline & \multicolumn{2}{|l|}{ G1 } & \multicolumn{2}{|l|}{ G2 } & \multicolumn{2}{|c|}{ G3 } & \multicolumn{2}{|l|}{ G4 } & \multicolumn{2}{|l|}{ G5 } \\
\hline & 230 & $74,68 \%$ & 70 & $26,22 \%$ & 46 & $25 \%$ & 99 & $41,08 \%$ & 68 & $55,28 \%$ \\
\hline $\begin{array}{l}\text { Substituição } \\
\mathrm{C}_{2}\end{array}$ & 27 & $8,77 \%$ & 108 & $40,45 \%$ & 71 & $38,59 \%$ & 53 & $21,99 \%$ & 23 & $18,7 \%$ \\
\hline $\begin{array}{l}\text { Apagamento } \\
\mathrm{C}_{1} \mathrm{C}_{2}\end{array}$ & 15 & $4,87 \%$ & 0 & $0 \%$ & 0 & $0 \%$ & 2 & $0,83 \%$ & 1 & $0,81 \%$ \\
\hline $\begin{array}{l}\text { Produção } \\
\mathrm{C}_{2} \mathrm{~V}\end{array}$ & 18 & $5,84 \%$ & 6 & $2,25 \%$ & 3 & $1,63 \%$ & 12 & $4,98 \%$ & 13 & $10,57 \%$ \\
\hline $\begin{array}{l}\text { Epêntese de } \\
\text { vogal }\end{array}$ & 1 & $0,32 \%$ & 51 & $19,10 \%$ & 53 & $28,8 \%$ & 62 & $25,73 \%$ & 15 & $12,20 \%$ \\
\hline $\begin{array}{l}\text { Inserção de } \\
\text { consoante }\end{array}$ & 0 & $0 \%$ & 4 & $1,50 \%$ & 2 & $1,09 \%$ & 1 & $0,41 \%$ & 0 & $0 \%$ \\
\hline Transposição & 2 & $0,65 \%$ & 10 & $3,75 \%$ & 6 & $3,26 \%$ & 10 & $4,15 \%$ & 0 & $0 \%$ \\
\hline Metátese & 2 & $0,65 \%$ & 6 & $2,25 \%$ & 3 & $1,63 \%$ & 1 & $0,41 \%$ & 0 & $0 \%$ \\
\hline $\begin{array}{l}\text { Movimento } \\
\text { recíproco }\end{array}$ & 10 & $3,25 \%$ & 2 & $0,75 \%$ & 0 & $0 \%$ & 1 & $0,41 \%$ & 2 & $1,63 \%$ \\
\hline Coalescência & 3 & $0,97 \%$ & 10 & $3,75 \%$ & 0 & $0 \%$ & 0 & $0 \%$ & 1 & $0,81 \%$ \\
\hline TOTAL & 308 & $100 \%$ & 267 & $100 \%$ & 184 & $100 \%$ & 241 & $100 \%$ & 123 & $100 \%$ \\
\hline
\end{tabular}

Tabela 3: Tipos de estratégia de reparo verificadas

Observa-se na Tabela 3 que as estratégias de reparo voltadas à posição $\mathrm{C}_{1}$ do CCV concentram-se nas produções do Grupo 1, também reunindo as maiores produções de Apagamento $\mathrm{C}_{1} \mathrm{C}_{2}$ e de Movimento Recíproco. A estratégia de Produção $\mathrm{C}_{2} \mathrm{~V}$, embora apresente maior quantidade absoluta no Grupo 1, é proporcionalmente maior no Grupo 5. Tal estratégia passa a ser pouco utilizada nos Grupos 2 e 3 e é em seguida retomada nas produções do Grupo 4 e 5, delineando uma Curva em U em sua aplicação na fala infantil. Já 
A. TONI Estratégias de reparo ao ataque ramificado $\mathrm{CCV}$ na aquisição fonológica no Grupo 2 tem-se maior quantidade das estratégias Metátese, Coalescência, Inserção de consoante e de substituições à posição $\mathrm{C}_{2}$, junto do Grupo 3. Este, por sua vez, tem a maior proporção de Epênteses vocálicas, enquanto o Grupo 4 apresenta maior percentual de Transposições. O Grupo 5, por fim, divide suas estratégias de reparo entre a Substituição $\mathrm{C}_{1}$ e as demais manipulações segmentais e silábicas, com destaque para a Substituição $\mathrm{C}_{2}$, a Produção $\mathrm{C}_{2} \mathrm{~V}$ e a Epêntese vocálica. Nota-se, pela tabela, que três estratégias de reparo são majoritariamente utilizadas nos cinco grupos perante as demais alterações segmentais ou silábicas: a Substituição $\mathrm{C}_{1}$, a Substituição $\mathrm{C}_{2}$ e a Epêntese vocálica. Somadas, tais estratégias representam 87\% do total de 1123 processos de manipulação segmental e silábica coletados no corpus.

Passando a examinar a estratégia de Substituição $C_{1}$, que ocorreu em exemplos como 'bruxa' ['gru.je] (Informante 23), 'Blico' ['dli.ko] (Informante 17), 'Craca' ['ta.ke] (Informante 9) e 'trigo' ['pi.ku]7 (Informante 14), observa-se na Tabela 4 abaixo que as modificações mais frequentes ao segmento oclusivo são a dessonorização, a substituição coronal $\rightarrow$ dorsal e, em ordem reversa, a substituição dorsal $\rightarrow$ coronal. Essas três modificações têm altas proporções de aplicação nos cinco grupos analisados. No Grupo 1 tem-se também alta quantidade de modificações coronal $\rightarrow$ labial, dorsal $\rightarrow$ labial e surda $\rightarrow$ sonora; no Grupo 2, destaca-se, também, a modificação oclusiva $\rightarrow$ fricativa; e no Grupo 3 e no Grupo 5 realça-se a substituição coronal $\rightarrow$ labial. Ressalta-se, portanto, que embora os segmentos coronais sobressaiam como alvos às modificações $\mathrm{C}_{1}$, tal como observado por Miranda (1996) e Ribas (2002), outros pontos de articulação e o traço de vozeamento também apresentam alta proporção de modificações, não parecendo haver uma alteração sistemática do ponto coronal ao ponto dorsal ou labial.

\begin{tabular}{|l|l|l|l|l|l|}
\hline \multirow{2}{*}{ Substituição C1 } & \multicolumn{5}{|c|}{ Ocorências } \\
\cline { 2 - 6 } & G1 & G2 & G3 & G4 & G5 \\
\hline oclusiva $\rightarrow$ fricativa & $6 / 230$ & $11 / 70$ & $0 / 46$ & $4 / 99$ & $4 / 68$ \\
\hline oclusiva $\rightarrow$ nasal & $3 / 230$ & $0 / 70$ & $0 / 46$ & $0 / 99$ & $0 / 68$ \\
\hline surda $\rightarrow$ sonora & $16 / 230$ & $3 / 70$ & $5 / 46$ & $8 / 99$ & $5 / 68$ \\
\hline sonora $\rightarrow$ surda & $57 / 230$ & $16 / 70$ & $9 / 46$ & $12 / 99$ & $9 / 68$ \\
\hline coronal $\rightarrow$ dorsal & $37 / 230$ & $12 / 70$ & $9 / 46$ & $41 / 99$ & $21 / 68$ \\
\hline coronal $\rightarrow$ labial & $52 / 230$ & $1 / 70$ & $8 / 46$ & $7 / 99$ & $11 / 68$ \\
\hline labial $\rightarrow$ coronal & $6 / 230$ & $7 / 70$ & $2 / 46$ & $5 / 99$ & $0 / 68$ \\
\hline labial $\rightarrow$ dorsal & $11 / 230$ & $3 / 70$ & $5 / 46$ & $3 / 99$ & $6 / 68$ \\
\hline dorsal $\rightarrow$ coronal & $23 / 230$ & $15 / 70$ & $6 / 46$ & $12 / 99$ & $9 / 68$ \\
\hline dorsal $\rightarrow$ labial & $19 / 230$ & $2 / 70$ & $2 / 46$ & $7 / 99$ & $3 / 68$ \\
\hline
\end{tabular}

Tabela 4: Descrição das alterações segmentais na estratégia de Substituição $C_{1}$

7 Nos casos em que ocorreu tanto a estratégia de Substituição $\mathrm{C}_{1}$ como de redução CCV > $\mathrm{C}_{1} \mathrm{~V}$, a produção foi classificada em ambas as categorias e considerada como duas entradas.
Revista Letras,

Curitiba, UfPr, n. 96, pp.255-286, jul./dez. 2017 ISSN 2236-0999 (versão eletrônica) 
Tratando da estratégia de Substituição $\mathrm{C}_{2}$, como em 'classe' ['kra.sI] (Informante 16), 'Crico' ['kli.ko] (Informante 15) e 'Blico' ['bwi.ko] (Informante 3), observa-se na Tabela 5 que, embora no Grupo 1 as estratégias de reparo direcionem-se à substituição do tepe pela líquida lateral e desta pelo glide, no Grupo 2 há uma distribuição equilibrada entre as alterações $/ l / \rightarrow / \mathrm{r} / \mathrm{e} / \mathrm{\varsigma} / \rightarrow / 1 /$. Nos Grupos 3, 4 e 5, por sua vez, nota-se preferência pela substituição da líquida lateral pelo tepe:

\begin{tabular}{|l|l|l|l|l|l|}
\hline \multirow{2}{*}{$\begin{array}{l}\text { Substituição } \\
\mathrm{C}_{2}\end{array}$} & \multicolumn{5}{|c|}{ Ocorrências } \\
\cline { 2 - 6 } & G1 & G2 & G3 & G4 & G5 \\
\hline$\Lambda / \rightarrow / \mathrm{r} /$ & $3 / 27$ & $51 / 108$ & $58 / 71$ & $34 / 53$ & $15 / 23$ \\
\hline$/ I / \rightarrow$ glide & $10 / 27$ & $3 / 108$ & $0 / 71$ & $0 / 53$ & $0 / 23$ \\
\hline$/ I / \rightarrow$ outros & $3 / 27$ & $2 / 108$ & $2 / 71$ & $0 / 53$ & $4 / 23$ \\
\hline$/ \mathrm{r} / \rightarrow / /$ & $7 / 27$ & $50 / 108$ & $4 / 71$ & $16 / 53$ & $4 / 23$ \\
\hline$/ \mathrm{r} / \rightarrow$ glide & $2 / 27$ & $0 / 108$ & $2 / 71$ & $1 / 53$ & $0 / 23$ \\
\hline$/ \mathrm{r} / \rightarrow$ outros & $2 / 27$ & $2 / 108$ & $5 / 71$ & $2 / 53$ & $0 / 23$ \\
\hline
\end{tabular}

Tabela 5: Descrição das alterações segmentais na estratégia de Substituição $C_{2}$

Em relação ao Apagamento $\mathrm{C}_{1} \mathrm{C} 2$, em que todo o ataque da sílaba $\mathrm{CCV}$ é suprimido, como em 'Dlato' ['a.to] (Informante 12), 'Tlido' ['i.do] (Informante 44) e 'classe' ['a.si] (Informante 29), observa-se na Tabela 6 que somente no Grupo 1 esta é uma estratégia produtiva, aplicando-se principalmente em sílabas de $\mathrm{C}_{2}$ lateral e $\mathrm{C}_{1}$ dorsal ou coronal.

\begin{tabular}{|l|l|l|l|l|l|l|}
\hline \multicolumn{2}{|l|}{$\begin{array}{l}\text { Apagamento } C_{1} C_{2} \\
\text { G1 }\end{array}$} & \multicolumn{5}{|c|}{ Ocorrências } \\
\cline { 3 - 8 } & G2 & G3 & G4 & G5 & \\
\hline \multirow{3}{*}{$C_{1}$} & coronal & $2 / 15$ & 0 & 0 & $0 / 2$ & $1 / 1$ \\
\cline { 2 - 8 } & labial & $5 / 15$ & 0 & 0 & $1 / 2$ & $0 / 1$ \\
\cline { 2 - 8 } & dorsal & $8 / 15$ & 0 & 0 & $1 / 2$ & $0 / 1$ \\
\hline \multirow{2}{*}{$C_{2}$} & lateral & $12 / 15$ & 0 & 0 & $2 / 2$ & $1 / 1$ \\
\cline { 2 - 8 } & tepe & $3 / 15$ & 0 & 0 & $0 / 2$ & $0 / 1$ \\
\hline
\end{tabular}

Tabela 6: Descrição das alterações segmentais na estratégia de Apagamento $C_{1} C_{2}$

Abordando a produção $\mathrm{C}_{2} \mathrm{~V}$, ou apagamento de $\mathrm{C}_{1}$, como em 'Blica' ['li. ke] (Informante 12), 'Craca' ['ra.ke] (Informante 10) e 'Drica' ['li.ke] (Informante 28), observa-se na Tabela 7 que os alvos produzidos são majoritariamente compostos por $\mathrm{C}_{2}$ lateral - somente 6 dados em todo o corpus compunham-se por líquida não-lateral, que foram substituídas pela líquida lateral em 5 das 6 ocorrências $\mathrm{C}_{2} \mathrm{~V}$, uma vez que o tepe não é um segmento permitido em início de palavra no $\mathrm{PB}$. Majoritariamente, segmentos de ponto de articulação coronal em $\mathrm{C}_{1}$ foram suprimidos na aplicação dessa estratégia. 
A. TONI

Estratégias de reparo ao ataque ramificado $\mathrm{CCV}$ na aquisição fonológica

\begin{tabular}{|l|l|l|l|l|l|l|}
\hline \multirow{2}{*}{ Produção $C_{2} V$} & \multicolumn{5}{|c|}{ Ocorrências } \\
\cline { 3 - 8 } \multicolumn{2}{|c|}{} & G1 & G2 & G3 & G4 & G5 \\
\hline \multirow{3}{*}{$C_{1}$} & coronal & $11 / 18$ & $3 / 6$ & $2 / 3$ & $8 / 12$ & $11 / 13$ \\
\cline { 2 - 7 } & labial & $2 / 18$ & $0 / 6$ & $1 / 3$ & $0 / 12$ & $1 / 13$ \\
\cline { 2 - 7 } & dorsal & $5 / 18$ & $3 / 6$ & $0 / 3$ & $4 / 12$ & $1 / 13$ \\
\hline \multirow{2}{*}{$C_{2}$} & lateral & $12 / 18$ & $6 / 6$ & $0 / 3$ & $11 / 12$ & $13 / 13$ \\
\cline { 2 - 7 } & tepe & $5 / 18$ & $0 / 6$ & $0 / 3$ & $1 / 12$ & $0 / 13$ \\
\hline
\end{tabular}

Tabela 7: Descrição das alterações segmentais na estratégia de Produção $\mathrm{C}_{2} \mathrm{~V}$

Quanto ao tipo de vogal a emergir entre as posições $\mathrm{C}_{1}$ e $\mathrm{C}_{2}$ na estratégia de Epêntese, como em 'bruxa' [bu'ru.je] (Informante 17), 'bravo' [be'ra.vo] (Informante 33) e 'blusa' [bo'lu.ze] (Informante 16), observa-se na Tabela 8 que somente uma dentre 181 ocorrências epentéticas do corpus apresentou vogal diferente de seu núcleo silábico, na palavra 'Blico' [ko'li.ko], em que uma vogal alta, posterior e arredondada emerge entre a /1/ e a oclusiva labial modificada à dorsal. No entanto, dada a dessemelhança entre a produção realizada pela criança e o alvo a ela apresentado, é possível que não tenha havido uma percepção correta do sujeito ao estímulo oferecido.

\begin{tabular}{|l|l|l|l|l|l|}
\hline \multirow{2}{*}{$\begin{array}{l}\text { Inserção de vogal } \\
\text { epentética }\end{array}$} & \multicolumn{5}{|c|}{ Ocorrências } \\
\cline { 2 - 6 } Cópia do núcleo CCV & $1 / 1$ & $51 / 51$ & $53 / 53$ & $62 / 62$ & $14 / 15$ \\
\hline Default [I] & $0 / 1$ & $0 / 51$ & $0 / 53$ & $0 / 62$ & $0 / 15$ \\
\hline Outra vogal & $0 / 1$ & $0 / 51$ & $0 / 53$ & $0 / 62$ & $1 / 15$ \\
\hline $\begin{array}{l}|c| \\
\text { Inserção de consoante } \\
\text { epentética }\end{array}$ & G1 & G2 & G3 & G4 & G5 \\
\hline /l/ & 0 & $1 / 4$ & $0 / 2$ & $1 / 1$ & 0 \\
\hline I/l & 0 & $1 / 4$ & $2 / 2$ & $0 / 1$ & 0 \\
\hline Outras consoantes & 0 & $2 / 4$ & $0 / 2$ & $0 / 1$ & 0 \\
\hline
\end{tabular}

Tabela 8: Descrição das alterações segmentais na estratégia de epêntese

Por sua vez, a estratégia de inserção de consoantes em sílabas CV (Tabela 8), formando encontros CCV, como em 'tromba' ['trõ.bre] (Informante 26) e 'Pupo' [plu.po] (Informante 25), pouco ocorreu nos dados da pesquisa. Cogitamos que esta inserção seja decorrente do priming fonológico gerado pela apresentação dos estímulos CCV aos informantes. A inserção consonantal também foi observada demarcando o preenchimento da posição $\mathrm{C}_{2}$ após ocorrência do processo de transposição, no exemplo 'Glapo' ['gar.plo] (Informante 25), em que uma parada glotal preenche a posição que a líquida lateral ocupa no input, e no exemplo 'Blabi' ['daw.bli] (Informante 17), em que um glide [w] foi adicionado à coda da sílaba portadora do CCV para demarcar sua transposição à sílaba seguinte

Revista Letras,

Curitiba, UFPR, n. 96, pp.255-286, jul./dez. 2017 ISSN 2236-0999 (versão eletrônica) 
(embora esta produção também possa indicar um mal entendimento do input pela criança).

Já quanto à transposição, como em 'Dlopo' ['do.plo] (Informante 12), 'Crico' ['ki.kro] (Informante 29) e 'Tlopo' ['to.blo] (Informante 39), vê-se na Tabela 9 abaixo uma preferência em direção ao ponto [labial], embora a baixa quantidade de aplicações deste reparo não permita cogitar generalizações. $\mathrm{O}$ mesmo pode ser observado à metátese, na Tabela 10, que tem produções como 'Pluto' ['pul.to] (Informante 8), 'Croco' ['kor.ko] (Informante 42) e 'trilho' ['tir. KO] (Informante 23).

\begin{tabular}{|l|l|l|l|l|l|}
\hline \multirow{2}{*}{ Transposição } & \multicolumn{5}{|c|}{ Ocorrências } \\
\cline { 2 - 6 } & G1 & G2 & G3 & G4 & G5 \\
\hline coronal $\rightarrow$ labial & $2 / 2$ & $6 / 10$ & $4 / 6$ & $9 / 10$ & 0 \\
\hline dorsal $\rightarrow$ labial & $0 / 2$ & $3 / 10$ & $2 / 6$ & $0 / 10$ & 0 \\
\hline coronal $\rightarrow$ coronal & $0 / 2$ & $1 / 10$ & $0 / 6$ & $0 / 10$ & 0 \\
\hline coronal $\rightarrow$ dorsal & $0 / 2$ & $0 / 10$ & $0 / 6$ & $1 / 10$ & 0 \\
\hline
\end{tabular}

Tabela 9: Descrição das alterações segmentais na estratégia de Transposição

\begin{tabular}{|l|l|l|l|l|l|l|}
\hline \multirow{2}{*}{ Metátese } & \multicolumn{5}{|c|}{ Ocorrências } \\
\cline { 3 - 8 } \multicolumn{2}{|c|}{} & G1 & G2 & G3 & G4 & G5 \\
\hline \multirow{3}{*}{$C_{1}$} & coronal & $1 / 2$ & $2 / 6$ & $1 / 3$ & $0 / 1$ & 0 \\
\cline { 2 - 8 } & labial & $1 / 2$ & $2 / 6$ & $1 / 3$ & $0 / 1$ & 0 \\
\cline { 2 - 8 } & dorsal & $0 / 2$ & $2 / 6$ & $1 / 3$ & $1 / 1$ & 0 \\
\hline \multirow{2}{*}{$C_{2}$} & lateral & $1 / 2$ & $4 / 6$ & $2 / 3$ & $0 / 1$ & 0 \\
\cline { 2 - 8 } & tepe & $1 / 2$ & $2 / 6$ & $1 / 3$ & $1 / 1$ & 0 \\
\hline
\end{tabular}

Tabela 10: Descrição das alterações segmentais na estratégia de Metátese

Relativamente ao processo de Movimento recíproco, como em 'clipe' ['pi. kI] (Informante 10), 'Tlico' ['kli.to] (Informante 37) e 'grupo' ['bu.ko] (Informante 8), tem-se na Tabela 11 abaixo a direção da substituição do C1 que continha o CCV no input. Poucos dados puderam ser coletados acerca desse processo, não sendo possível estabelecer generalizações. Do mesmo modo, também acerca do processo de Coalescência, na Tabela 12, não é possível estabelecer generalizações devido a sua baixa produtividade nos dados. Ocorrências desse processo produzem-se em exemplos como 'bruxa' ['vu.te] (Informante 14) e 'blusa' ['flu. te] (Informante 18). 
A. TONI

Estratégias de reparo ao ataque ramificado $\mathrm{CCV}$ na aquisição fonológica

\begin{tabular}{|l|l|l|l|l|l|}
\hline \multirow{2}{*}{ Movimento recíproco } & \multicolumn{5}{|c|}{ Ocorrências } \\
\cline { 2 - 7 } & G1 & G2 & G3 & G4 & G5 \\
\hline coronal $\rightarrow$ labial & $2 / 10$ & $0 / 2$ & 0 & $0 / 1$ & $0 / 2$ \\
\hline dorsal $\rightarrow$ labial & $7 / 10$ & $0 / 2$ & 0 & $0 / 1$ & $0 / 2$ \\
\hline coronal $\rightarrow$ dorsal & $1 / 10$ & $0 / 2$ & 0 & $1 / 1$ & $2 / 2$ \\
\hline labial $\rightarrow$ dorsal & $0 / 10$ & $2 / 2$ & 0 & $0 / 1$ & $0 / 2$ \\
\hline
\end{tabular}

Tabela 11: Descrição das alterações segmentais na estratégia de Movimento recíproco

\begin{tabular}{|c|c|c|c|c|c|c|}
\hline \multicolumn{2}{|c|}{ Coalescência } & \multicolumn{5}{|c|}{ Ocorrências } \\
\hline & & G1 & G2 & G3 & G4 & G5 \\
\hline \multirow{3}{*}{$\mathrm{C}_{1}$} & coronal & $0 / 3$ & $3 / 10$ & 0 & 0 & $1 / 1$ \\
\hline & labial & $1 / 3$ & $7 / 10$ & 0 & 0 & $0 / 1$ \\
\hline & dorsal & $2 / 3$ & $0 / 10$ & 0 & 0 & $0 / 1$ \\
\hline \multirow{2}{*}{$\mathrm{C}_{2}$} & lateral & $1 / 3$ & $9 / 10$ & 0 & 0 & $1 / 1$ \\
\hline & tepe & $2 / 3$ & $1 / 10$ & 0 & 0 & $0 / 1$ \\
\hline
\end{tabular}

Tabela 12: Descrição das alterações segmentais na estratégia de Coalescência

\section{Analisando a aplicação de estratégias de reparo ao ataque ramificado CCV: motivação fonológica ou articulatória?}

Conforme observado na Tabela 1 na seção anterior, o corpus analisado nesta pesquisa apresentou diferentes percentuais de realização-alvo do CCV, variando entre $0 \%$ a $85 \%$. Já a redução CCV > $\mathrm{C}_{1} \mathrm{~V}$ variou entre 1,33\% a 87,72\% dos estímulos apresentados no estudo e a aplicação das estratégias de reparo, enfoque do presente trabalho, variou entre $10 \%$ e $61,84 \%$, tendo ocorrido nas produções dos cinco grupos de desenvolvimento CCV.

Ressaltando as estratégias aplicadas à líquida a ocupar a posição $\mathrm{C}_{2}$ do ataque ramificado, observamos no estudo experimental que, enquanto em G1 as líquidas laterais são majoritariamente manipuladas por meio de estratégias de reparo, tem-se em G2 - o grupo que representa o início da produtividade das realizações-alvo CCV na fala infantil - uma proporção equilibrada entre os tipos de líquida modificados pelas crianças - o que sugere a ausência de uma ordenação específica no desenvolvimento dos ataques ramificados, tal como defendido por Ribas (2002). No entanto, a partir de G3 a aplicação de estratégias de reparo passa a ter proporções de aplicação significativamente maiores em sílabas compostas por líquida lateral. A este padrão de produção cogitamos duas possíveis explicações, assinalando que, em ambas, a direção das modificações segue o processo de rotacismo8 presente na fala adulta (TRENNEPHOL DA

Revista Letras,

8 Rotacismo é definido como "um processo de alternância entre as consoantes líquidas, lateral e rótico,

Curitiba, UfPR, n. 96, pp.255-286, jul./dez. 2017 ISSN 2236-0999 (versão eletrônica) 
COSTA, 2013). Inicialmente, destacamos que a presença das sequências raras $/ \mathrm{tl}$, dl/ poderia causar um aumento na proporção de estratégias de reparo aplicadas à $\mathrm{C} / \mathrm{l} / \mathrm{V}$ nos dados da pesquisa. Paralelamente, tem-se a presença de logatomas no corpus, significativamente mais manipulados que as palavras familiares em nosso estudo, e que apresentavam maior quantidade de estímulos contendo contextos de líquida lateral. Dado que somente nos grupos G4 e G5 foi observada diferença significativa entre a proporção de estratégias de reparo aplicadas a oclusivas coronais em relação às oclusivas labiais e dorsais, consideramos que ambas as justificativas podem estar agindo, em momentos diferentes, na fala infantil: nos grupos G1, G2 e G3 é possível que as palavras inventadas como um todo estejam sendo mais manipuladas pelos informantes, num possível reconhecimento do caráter incomum de tais palavras, e não, propriamente, de suas sequências fonotáticas com líquida lateral; já os grupos G4 e G5 apresentariam, significativamente, maior proporção de manipulações em contextos de líquidas laterais em posição $\mathrm{C}_{2}$ e oclusivas coronais em posição $\mathrm{C}_{1}$, indicando que neles as combinações fonotáticas / $\mathrm{t} \mathrm{l}, \mathrm{dl} /$ compõem os alvos preferenciais das modificações silábicas - apresentando um reconhecimento da infrequência destas combinações fonotáticas e não, propriamente, da natureza dos estímulos selecionados. De fato, a maior quantidade de manipulações gerada pelo emprego de logatomas no experimento possibilitou a observação de padrões preferenciais para as alterações aplicadas no ataque ramificado. Observou-se no grupo $\mathrm{G} 1$ que a posição $\mathrm{C}_{1}$ foi majoritariamente visada pelas crianças que ainda não articulam com produtividade as realizações-alvo do CCV; salientamos, também, que mesmo nesse grupo G1 houve aplicação de estratégias de reparo visando modificar a qualidade da líquida em posição $\mathrm{C}_{2}$, o que pode indicar a presença incipiente da estrutura CCV também em suas produções. Majoritariamente, a alteração segmental das líquidas em G1 visava a produção de glides nas sílabas $\mathrm{C} / \mathrm{l} / \mathrm{V}$ e de laterais nas sílabas $\mathrm{C} / \mathrm{r} / \mathrm{V}$, apesar de haver também modificações da lateral em direção à não-lateral e à vocalização do tepe. No entanto, é de se notar que o padrão $/ / \rightarrow$ glide e $/ \mathrm{r} / \rightarrow / /$ não se manteve ao longo dos grupos analisados: além do gradual desuso do glide, observou-se um aumento, a partir de G2, nas modificações da lateral em direção à não-lateral, num movimento de rotacização que poderíamos considerar como hipercorretivo ou de aproximação à frequência fonotática produtivamente mais observada no input - uma vez que a líquida não-lateral apresenta tanto maior número de combinações CCV (/pr, $\mathrm{br}, \mathrm{kr}, \mathrm{gr}, \mathrm{tr}, \mathrm{dr} /$ versus /pl, bl, kl, gl/) quanto maior percentual de uso na língua alvo que as combinações com /1/ (ALBANO, 2001; TONI, 2016). Destacamos, assim, que a preferência pela consoante lateral, segmento prototípico da classe das líquidas (HERNANDORENA; LAMPRECHT, 1997), deixa de ocorrer a

no ambiente de ataque complexo, como a realização de 'plano' ou 'prano'. (...) " (TRENNEPHOL DA COSTA, 2013, p. 179). Citando Câmara Jr, a autora aponta: "'[...] Nos grupos de líquida como segundo elemento consonântico, há nos dialetos sociais populares o rotacismo do 'l' que muda em 'r' (CÂMARA JR, 1972, p. 40-41; TRENNEPHOL DA COSTA, 2013, p. 179). 
A. TonI Estratégias de reparo ao ataque ramificado $\mathrm{CCV}$ na aquisição fonológica

partir de G2, movimento também acompanhado por um aumento na proporção de realizações-alvo de sílabas $\mathrm{C} / \mathrm{r} / \mathrm{V}$, conforme observado na Tabela 1.

Questionando o motivo pelo qual as estratégias de reparo ainda seriam aplicadas na fala infantil a partir do Grupo 2, cogitamos que a própria aquisição tardia dos segmentos licenciados à posição $\mathrm{C}_{2} \mathrm{da}$ sílaba $\mathrm{CCV}$ poderia constituir uma motivação possível ao emprego produtivo dos processos de reparo e de redução CCV a C 1 V. Segundo Hernandorena e Lamprecht (1997) e Mezzomo \& Ribas (2004), as líquidas compõem a classe de sons de aquisição mais tardia no PB, estabilizando-se em posição de ataque simples aos 3;0 anos, para /l/, e 4;2 anos, para $/ \mathrm{r} /$. Deste modo, a aquisição tardia das líquidas pode explicar o baixo uso de estratégias de reparo como a Produção $\mathrm{C}_{2} \mathrm{~V}$ e a Epêntese vocálica no Grupo 1, já que ambas são modificações estruturais que geram sílabas CV assim como a redução $\mathrm{C}_{1} \mathrm{~V}$ : enquanto este último reparo suprime a produção das líquidas, processos como a Epêntese e a Produção $\mathrm{C}_{2} \mathrm{~V}$ exigem sua articulação, sendo portanto preteridas uma vez que a dificuldade segmental evitada pela criança por meio da aplicação da estratégia de reparo ainda seria mantida em sua realização. Contudo, dada a aquisição dos segmentos líquidos, passamos a indagar o motivo pelo qual também nos dados dos grupos G2 a G5 - em que ao menos a aquisição da líquida lateral já estaria estabilizada segundo resultados de Hernandorena e Lamprecht (1997) - ainda poderiam ser encontradas estratégias de reparo simplificando os ataques ramificados na fala da criança. Especificamente, nos perguntamos por que reparos como a Redução $\mathrm{C}_{1} \mathrm{~V}$ ainda continuam a ser aplicados em G2-G5, em detrimento a reparos somente orientados a modificar a qualidade da líquida em $\mathrm{C}_{2}$ mas manter o molde CCV na produção da criança. Cogitamos que não só a produção das líquidas em termos de período de aquisição ofereceria dificuldades à produção infantil, mas também a própria combinação de ponto de articulação desta consoante ao segmento em posição $\mathrm{C}_{1}$ no CCV. Estudos fonotáticos apontam que as combinações segmentais licenciadas a compor as posições silábicas de uma língua podem ser regidas pelo Princípio do Contorno Obrigatório (OCP) proposto por Leben (1973) e Goldsmith (1976) à Fonologia tonal e adaptado às línguas não-tonais por McCarthy (1986). Nele, postula-se a proibição de elementos idênticos adjacentes num mesmo plano melódico, como na camada segmental. Tomando como base este princípio (que nem sempre apresenta efeitos categóricos, segundo Goch (2010)), nota-se que a combinação /t, $\mathrm{d} /+/ \mathrm{l}, \mathrm{r} /$ apresenta em ambas as posições $\mathrm{C}_{1}$ e $\mathrm{C}_{2}$ segmentos contendo traço [coronal], o que pode justificar sua baixa produtividade nos grupos G1 a G5. Efeitos do OCP também poderiam explicar a maior dificuldade de produção do grupo velar em comparação ao grupo labial, na produção de combinações como /kl, gl/, dado que, em Português, considera-se que a líquida lateral também apresenta ponto [dorsal] em sua hierarquia de traços (WALSH, 1995 apud CRUZ, 2009). Deste modo, somente as combinações C/l/V e C/r/V contendo oclusivas labiais - aquelas apontadas como significativamente menos

Revista Letras,

Curitiba, UfPr, n. 96, pp.255-286,

jul./dez. 2017 ISSN 2236-0999 (versão eletrônica) 
atingidas pelos reparos CCV em nosso estudo, assim como em Miranda (1996) e Ribas (2002) - não seriam suscetíveis aos efeitos deste princípio, que é observado como influente tanto sobre traços de ponto como de modo de articulação e vozeamento em línguas como o Árabe, o Latim e o Japonês (GOCH, 2010) e ao qual se atribuem as frequências restritas das sequências / $\mathrm{tl}$, $\mathrm{dl} /$ em línguas como o Inglês e o Espanhol (HARRIS, 1983; BRADLEY, 2005). Em resumo, podemos inferir que o OCP não só estaria atuando em G2-G5, mas também em G1.

Há também argumentos de base articulatória para procurar explicar o desuso não categórico de estratégias de reparo como a redução $\mathrm{C}_{1} \mathrm{~V}$ e a substituição das líquidas mesmo em grupos ou faixas em que alta produtividade do molde CCV se faz presente, assim como a estabilização dos segmentos líquidos. Goldstein (2003 apud BERTI e FERREIRA-GONÇALVES, 2012) aponta acerca do desenvolvimento dos gestos articulatórios na fala infantil que:

(...) as crianças aprendem, num período inicial do controle motor da fala, a diferenciar os articuladores (nos termos do autor "between-organ contrast"), como, por exemplo: lábios vs. língua. Em um segundo momento, há um refinamento do controle neuromotor e, assim, as crianças aprendem a diferenciação intra-articuladores (nos termos desse autor "within-organ contrast"), como, por exemplo, ponta da língua vs. corpo da língua. E, posteriormente, na medida em que as crianças vão sendo capazes de diferenciar e movimentar os principais articuladores independentemente, elas, então, passam ao ajuste do grau e do local de constrição desses articuladores. (GOLDSTEIN, 2003, p. 86 apud BERTI e FERREIRA-GONÇALVES, 2012, p. 187)

Com isso, notamos que a combinação fonotática de menor produtividade na fala infantil, /t, d/ em $\mathrm{C}_{1}+/ 1$, r/ em $\mathrm{C}_{2}$, apresenta, em sequência, duas consoantes que devem ser pronunciadas pelo mesmo articulador e sob o mesmo ponto de articulação (mas em modos de articulação diferentes), contexto de maior exigência motora segundo o texto referido acima; já combinações do tipo /k, g/ + /l, r/ apresentam mesmos articuladores, mas pontos de articulação distintos (diferentes intra-articuladores, nos termos dos autores citados); e por fim, as combinações labiais + líquidas, como /br, bl/, apresentam não só pontos de articulação diferentes mas também articuladores distintos - o primeiro contexto motor a ser dominado pela criança segundo Goldstein (2003). Em suma, nas combinações /p, b/ + /1, s/ parece haver menor dificuldade à produção do ataque ramificado à medida que, enquanto um articulador (os lábios) produz a closura e consequente burst oclusivo, o outro (a língua) prepara-se para produzir a conformação das líquidas. Com isso, podemos explicar a evitação às combinações coronais observada em nossos resultados, assim como embasar a preferência pelas combinações labiais 
A. TonI Estratégias de reparo ao ataque ramificado $\mathrm{CCV}$ na aquisição fonológica
Revista Letras,

Curitiba, UFPR,

n. $96, \mathrm{pp} .255-286$,

jul./dez. 2017

ISSN 2236-0999

(versão eletrônica) que atingem as consoantes em posição $\mathrm{C}_{1}-\mathrm{e}$, ainda, excluir destas preferências as combinações dorsais $/ \mathrm{kr}$, gr/, distinção não capturada pelo princípio do OCP acima. Corroborando esta sugestão de uma provável causa articulatório-motora (além da causa fonológica do $\mathrm{OCP}$ ) à evitação de $\mathrm{CCV}$ s coronais e à preferência por CCVs labiais, reportamos os estudos fonoaudiológicos de Ribas $(2002,2006)$, que propõem as combinações fonotáticas / br/ e /pl/ como facilitadoras ao processo terapêutico dado o desempenho estatisticamente significativo de crianças de fala típica e atípica nas realizações-alvo desta combinação segmental, além do estudo de Giacchini, Mota e Mezzomo (2011), que observaram maior eficiência no uso de terapias fonoaudiológicas de base fonética 9 em comparação àquelas de base fonológica10 no tratamento de crianças com desvio fonoaudiológico.

Sintetizando os argumentos acima - advindos das estratégias de reparo do CCV; da conformação fonológica e articulatória-motora das combinações labial, coronal e dorsal + líquidas; da evitação das combinações coronal + líquida e preferência pela labial + líquida; e da diferença nas terapêuticas fonoaudiológicas que contribuem à superação da redução $\mathrm{CCV}$ a $\mathrm{C}_{1} \mathrm{~V}-11$, cogitamos que tanto marcações fonológicas quanto dificuldades motoras ((co)articulatórias) podem ser tomadas como motivação à aplicação de estratégias de reparo ao molde CCV nos outputs infantis. Consideramos válido ressaltar, contudo, que estes fatores coarticulatórios e fonológicos não parecem agir sozinhos nas produções da criança, uma vez que mesmo no Grupo G1 sílabas CCV contendo oclusivas coronais podem não sofrer estratégias de reparo - assim como também foram coletadas sílabas com $\mathrm{C}_{1}$ labial que sofreram reparos no corpus. É possível, deste modo, que fatores como a situação e velocidade de fala, a realização isolada da palavra ou sua posição na sentença, dentre outros fatores, possam, igualmente, influenciar a realização, supressão ou modificação dos segmentos em posição $\mathrm{C}_{1}$ e $\mathrm{C}_{2}$ nas sílabas CCV - e embora essa investigação fuja ao escopo da presente pesquisa, esperamos num estudo futuro poder observar a influência de possíveis outros fatores que poderiam afetar a produção da ramificação de ataque na fala da criança.

\footnotetext{
9 Terapia que visa "realizar os movimentos coordenados e precisos que a articulação dos fones exige. As atividades envolveram estimulação tátil da região oral, treino de tensão e distensão dos órgãos fonoarticulatórios e seu treino motor. Foram utilizadas estimulações visuais, figuras, animações e fotos que demonstraram o movimento dos lábios, língua e mandíbula durante a produção do som-alvo" (GIACHINI et al., 2011, p. 59)

10 Terapia "baseada no Modelo de Pares Mínimos, contrastando a estrutura silábica. As atividades aplicadas foram planejadas com o intuito de tirar vantagem da confusão semântica (criação de homônimos) criada por um erro de produção, dando destaque para as quebras na comunicação quando da não realização da estrutura silábica adequada" (GIACHINI et al., 2011 p. 59)

11 Apontamos, também, o estudo de Miranda (2011, p. 22), que reporta uma comunicação pessoal com Larissa Berti em que a fonoaudióloga relata "que suas investigações preliminares com imagens de ultrassom indicam que a criança que está adquirindo a sílaba CCV busca atingir os alvéolos de maneira gradiente. Ou seja, com movimentos em direção aos alvéolos sem tocá-los inicialmente. Tal estratégia articulatória busca construir uma rotina motora que, eventualmente, venha a produzir a obstrução do tepe" - o que poderia também evidenciar uma manifestação do reconhecimento do molde CCV pela criança enquanto a produção do CCV ainda é realizada como as formas reduzidas a ataques simples.
} 


\section{Referências}

ALBANO, E. C. O gesto e suas bordas: esboço de fonologia acústico-articulatória do português brasileiro. Campinas: Mercado de Letras, 2001.

ALONSO, A. Estudios lingüísticos: temas hispanoamericanos. Madrid: Gredos, 1953.

BAESSO, J. S. O uso de estratégias de reparo nos constituintes coda e ataque complexo por crianças com aquisição fonológica normal e desviante. Dissertação (Mestrado em Distúrbios da Comunicação Humana), UFSM, Santa Maria, 2009.

BISOL, L. A sílaba e seus constituintes. In: NEVES, M. H. de M. (Ed.). Gramática do português falado. v. 7: Novos Estudos. Campinas: Editora UNICAMP, 1999. p. 701-742.

BRADLEY, T. G. Contrast and Markedness in Complex Onset Phonotactics. Southwest Journal of Linguistics, v. 25, n.1, p. 29-58. 2005.

BRADLEY, T. G.; SCHMEISER, B. On the phonetic reality of $/ \mathrm{R} /$ in Spanish complex onsets. In: KEMPCHINSKY, P. M.; LISKIN-GASPARRO, J.; PIÑEROS, C. E. (Ed.). Selected proceedings of the sixth Hispanic Linguistics Symposium. Somerville, MA: Cascadilla Press. 2005. p. 1-20.

CÂMARA JR., J. M. Para o estudo da fonêmica portuguesa. $2^{\mathrm{a}}$ ed., Rio de Janeiro: Padrão, 1977.

COLLISCHONN, G. A sílaba em Português. In: BISOL, L. (Ed.) Introdução a estudos de fonologia do português brasileiro. Porto Alegre: Edipucrs, [1996]1999.

CRAIN, S.; THORNTON, R. Investigations in Universal Grammar: A guide to experiments on the acquisition of syntax and semantics. Cambridge, MA: The MIT Press, 2000.

CRUZ, G. F. A. O processo de semivocalização de líquidas laterais em posição pré-vocálica: uma revisão teórica. Letrônica, Porto Alegre, v. 2, n. 2, p. 48-57, dez. 2009.

FERRANTE C.; BORSEL J. V.; PEREIRA M. M. B. Análise dos processos fonológicos em crianças com desenvolvimento fonológico normal. Rev Soc Bras Fonoaudiol. v. 14, n.1, p. 36-40, 2009.

FIKKERT, P. On the acquisition of rhyme structure in Dutch. In: BOKBENNEMA, R.; CREMERS, C. (Ed.). Linguistics in the Netherlands. Amsterdam: John Benjamins, 1994. p. 37-48.

FREITAS, M. J. A aquisição da estrutura silábica do português europeu. 396 p. Tese (Doutorado em Linguística), Universidade de Lisboa, Lisboa, 1997. 
A. TonI

Estratégias de reparo ao ataque ramificado $\mathrm{CCV}$ na aquisição fonológica
GIACCHINI, V.; MOTA, H. B.; MEZZOMO, C. L. Diferentes modelos de terapia fonoaudiológica nos casos de simplificação do onset complexo com alongamento compensatório. Rev. CEFAC, v. 13, n. 1, jan./fev. . 2011.

GOCH, W. van. The Obligatory Contour Principle: Consonant co-occurrence restrictions in Dutch. Dissertação (Mestrado em Taal, Mens en Maatschappij), Universidade de Utrecht, Utrecht, 2010.

GOLDSMITH, J. Autosegmental phonology. Tese (Doutorado em Linguística), MIT, Cambridge, 1976.

GOLDSTEIN, L. Emergence of discrete gestures. In: SOLÉ, M. J., RECASENS, D.; ROMERO, J. (Ed.). Proceedings of the 15th International Congress of Phonetic Sciences. Barcelona: Universidade Autônoma de Barcelona. 2003. p. 85-88.

GORDON, M. A phonetically-driven account of syllable weight. Language, v. 78, p. 51-80, 2004.

GREENLEE M. Interacting processes in the child's acquisition of stop-liquid clusters. Papers and Reports on Child Language Development. v. 7, p. 85-100, 1974.

GROLLA, E. Metodologias Experimentais em Aquisição da Linguagem. Estudos da Lingua(gem), v. 7, p. 9-42, 2009.

HARRIS, J. Syllable structure and stress in Spanish: a nonlinear analysis. Cambridge: MIT Press, 1983.

HERNANDORENA, C. M.; LAMPRECHT, R. R. A aquisição das consoantes líquidas do português. Letras de Hoje, Porto Alegre, v. 32, n. 4, p. 7-22, 1997.

JAKOBSON, R. (1968). Child language, aphasia and phonological universals. The Hague: Mouton. (Originalmente publicado como Kindersprache, Aphasie und allgemeine Lautgesetze em 1941)

LAMPRECHT, R. R. A aquisição da fonologia do Português na faixa etária dos 2:9-5:5. Letras de Hoje, Porto Alegre, v. 28, n.2, p.99-106, jun. 1993.

LAMPRECHT, R.R. Antes de mais nada. In: LAMPRECHT, R. R (Ed.), Aquisição fonológica do Português: Perfil de desenvolvimento e subsídios para terapia. Porto Alegre: Artes Médicas, 2004, p. 17-32.

LAMPRECHT, R. R (Ed.), Aquisição fonológica do Português: Perfil de desenvolvimento e subsídios para terapia. Porto Alegre: Artes Médicas, 2004.

LEBEN, W. Suprasegmental Phonology. PhD dissertation, MIT. Distributed by Indiana University Linguistics Club. 1973.

LEONARD, L. B. Deficiência fonológica. In: FLETCHER, P.; MacWHINNEY, B. Compêndio da linguagem da criança. Porto Alegre: Artes Médicas, 1997. p. 573-602.
Revista Letras,

Curitiba, UFPR,

n. 96, pp.255-286,

jul./dez. 2017

ISSN 2236-0999

(versão eletrônica) 
MAGALHÃES, J. S. A metátese da líquida não-lateral na aquisição: evidência para o pé troqueu. Letras de Hoje, Porto Alegre, v. 38, n. 2, p. 83-95, jun. 2003.

MARQUES, J. Estruturas silábicas do português do Brasil: Uma análise tipológica. Dissertação (Mestrado em Linguística), Universidade de São Paulo, São Paulo, 2008.

MCCARTHY, J. "OCP effects: gemination and antigemination. Linguistic Inquiry, v. 20, p. 71-99. 1986.

MEZZOMO, C. L.; RIBAS, L. P. Sobre a aquisição das líquidas. In: LAMPRECHT, R. R. et al. Aquisição fonológica do português: perfil de desenvolvimento e subsídios para terapia. Porto Alegre: Artmed, 2004. p. 95109.

MIRANDA, I. C. C. Aquisição e variação estruturada de encontros consonantais tautossilábicos. Tese (Doutorado em Linguística) - Faculdade de Letras, UFMG, Belo Horizonte. 2007.

MIRANDA, I. C. C; SILVA, T. C. Aquisição de encontros consonantais tautossilábicos: uma abordagem multirrepresentacional. Revista Lingüistica, v. 7, n. 1, jun. 2011.

MONTENEGRO, A. C. A. Aquisição do onset complexo $C(r)$ no português: uma abordagem multidimensional. Tese (Doutorado em Linguística), Universidade Federal de Pernambuco, Recife, 2012.

MOTA, A.; OTHERO, G.; FREITAS, J. A análise dos processos fonológicos. 2001. Não impresso.

MIRANDA, A. R. M. A aquisição do 'r': uma contribuição à discussão sobre seu status fonológico. 125 p. Dissertação (Mestrado em Letras) - Pontifícia Universidade Católica do Rio Grande do Sul, Porto Alegre, 1996.

NESPOR, M.; Vogel, I. Prosodic Phonology. Dordrecht: Foris Publications. 1986.

NISHIDA, G. A natureza intervocálica do tepe em PB. Dissertação (Mestrado em Linguística), Curitiba, Universidade Federal do Paraná, 2009.

REDMER, C. Metátese e Epêntese na Aquisição da Fonologia do Português - uma análise com base na Teoria da Otimidade. Dissertação (Mestrado em Letras) Escola de Educação, Universidade Católica de Pelotas, Pelotas, 2007.

RIBAS, L. Aquisição do Ataque Complexo. Dissertação (Mestrado em Letras) Pontifícia Universidade Católica do Rio Grande do Sul, Porto Alegre, 2002.

Onset complexo nos desvios fonológicos: descrição, contribuições para teoria, subsídios para terapia. 2006. Tese (Doutorado em Letras) - Pontifícia Universidade Católica do Rio Grande do Sul, Porto Alegre, 2006. 
A. TonI Estratégias de reparo ao ataque ramificado $\mathrm{CCV}$ na aquisição fonológica
SANTOS, R. S. Aquisição da estrutura silábica. Letras de Hoje, n. 112, Porto Alegre: EDIPUC-RS, 1998.

SCARPA, E. The development of intonation and dialogue processes in two Brazilian children. 1984. Tese (Doutorado) - University of London, Londres, 1984.

SCHMEISER, B. On the Current State of Vowel Intrusion Analysis in Spanish within Optimality Theory. In: COLLENTINE et al. (eds.), Selected Proceedings of the 11th Hispanic Linguistics Symposium, 2009, Somerville, MA: Cascadilla Proceedings Project, p. 207-218.

SCHWINDT, L. C. O prefixo no português brasileiro: análise prosódica e lexical. DELTA [online], vol.17, n.2, p. 175-207, 2001.

SELKIRK, E. The Syllable. In: HULST, H.; SMITH, N. (Ed.). The Structure of Phonological Representations (Part II). Dordrecht: Foris. 1982. p. 337-383.

SILVEIRA, F.; SEARA, I. C. Vogal de apoio em grupos consonantais CCV do Português Brasileiro. Revista da ABRALIN, v. 7, n. 1, p. 27-47, jan./jun. 2008.

TEIXEIRA, E. R. Processos de simplificação fonológica como parâmetros maturacionais em português. Cadernos de estudos linguísticos, n. 14, p. 53-63, 1988.

TONI, A. Representação subjacente do ataque ramificado CCV na aquisição fonológica. Dissertação (Mestrado em Linguística) -Universidade de São Paulo, São Paulo, 2016.

TRENNEPHOL DA COSTA, L. Fenômenos variáveis e variantes líquidas produzidas no ataque complexo. Acta Scientiarum. Language and Culture. Maringá, v. 35, n. 2, p. 179-186, abr.jun. 2013.

VIARO, M. E.; GUIMARÃES FILHO, Z. O. Análise quantitativa da freqüência dos fonemas e estruturas silábicas portuguesas. Estudos Lingüísticos, São Paulo, v. 36, p. 28-36, 2007.

WALSH, L. Representing Laterals. In: BECKMAN, J. N. (Ed.) Proceedings of the Noth-East Linguistics society 25. v.2, GLSA (Graduate Linguistic Student Association), Amherst MA, 1995, p. 535-548.

WERTZNER, H. F. Fonologia. In: ANDRADE, C. R. F.; BEFI-LOPES, D. M.; FERNANDES, F. D. M.; WERTZNER, H. F. ABFW: Teste de linguagem infantil nas áreas de Fonologia, Vocabulário, Fluência e Pragmática. São Paulo: PróFono, 2000. p. 5-40.

WERTZNER, H. F.; SANTOS, P; PAGAN-NEVES, L. O. Tipos de erros de fala em crianças com transtorno fonológico em função do histórico de otite média. Revista da Sociedade Brasileira de Fonoaudiologia (Impresso), v. 17, p. 422429, 2012.
Revista Letras,

Curitiba, UfPr, n. 96, pp.255-286, jul./dez. 2017 ISSN 2236-0999 (versão eletrônica) 
YAVAS, M., HERNANDORENA, C. L. M.; LAMPRECHT, R. R. Avaliação fonológica da criança. Porto Alegre: Artes Médicas, 1991.

Submetido em: 31-01-2017

Aceito em: 15-06-2017 